\title{
LA CONDUCTA MODERNA EN EL PALEOLÍTICO SUPERIOR INICIAL
}

\author{
The modern behavior in the initial upper Paleolithic
}

\author{
Ángel Rivera Arrizabalaga ${ }^{1}$
}

Recibido el 20 de julio de 2009. Aceptado el 6 de octubre de 2009.

Resumen: La conducta moderna y simbólica aparece definitivamente con el comienzo del Paleolítico Superior. Sin embargo, en los estudios arqueológicos basados en su análisis no incluyen el uso de ciencias específicas como la Psicología y Neurología. No hay razón para aislar estos campos científicos, de hecho parece ser importante su utilización para una mejor comprensión de nuestro comportamiento simbólico. El presente estudio constituye la aplicación de un modelo sobre el desarrollo de la conducta humana basado en estas ciencias (Arqueología Cognitiva: orientación psicobiológica), sobre los datos de la última transición paleolitica en Europa, para clarificar el origen de estas culturas modernas.

Palabras clave: Arqueología Cognitiva. Desarrollo cognitivo. Conducta moderna. Simbolismo.

Abstract: The modern and symbolic behavior appears definitely in the beginning of the Upper Paleolithic. Nevertheless, in the archaeological studies based on its analysis don't include the use of specific science such as Psychology and Neurology. There is no reason to isolate these scientific fields, in fact it seems to be important its use for a better understanding of our symbolical behavior. The current study constitutes the application of a model of the development of the human behavior based on these sciences (Cognitive Archaeology: Psychobiological orientation), to the data of the last Paleolithic transition in Europe, in order to clarify the origin these modern cultures.

Key Words: Cognitive Archaeology. Cognitive development. Modern behavior. Symbolism.

El estudio del origen y desarrollo de la conducta humana en el paleolítico presenta importantes problemas. Entre ellos adquieren especial relevancia la tradicional escasez de información, así como la falta de un método que encauce su realización. Si respecto del primero sólo se puede seguir la actual línea de trabajo arqueológica, del segundo parece lógico intentar elaborar formas de estudio que permitan su realización con las mayores garantías científicas posibles. En este sentido, al no conocer los elementos que caracterizan la cognición del pasado, la única seguridad objetiva que podemos tener son nuestras propias características neurológicas y psicológicas (psicobiológicas) originadas por los procesos evolutivos, pues contienen unos elementos estructurales sobre los que parece posible iniciar tal estudio. Para la realización de tal método es importante tener un conocimiento básico sobre la forma evolutiva de las cualidades biológicas de nuestro cerebro, caracteristicas generales de la psicología humana, asi como de la relación de las sociedades entre sí y con el medio ambiente con el que interaccionan. La estrecha interconexión de recientes conceptos de la Neurología, Psicología, Sociología y Biología Evolutiva hace posible la creación de un modelo de evolución conductual que satisfaga, al menos en parte, tales aspiraciones (Rivera Arrizabalaga, 2004, 2009). 


\section{CARACTERÍSTICAS PSICOBIOLÓGICAS DE LA CONDUCTA HUMANA}

Lo único común a todos los humanos que podamos utilizar de una manera objetiva sería la estructura psicobiológica propia de nuestro género, la cual puede aplicarse tanto a los seres humanos actuales como a los que desarrollaron las culturas del paleolítico. Estas características ofrecen un panorama fácilmente identificable con un estructuralismo funcional, es decir, con la base funcional sobre la que se va a desarrollar nuestro pensamiento y conducta. Los sentidos de percepción de la naturaleza y su procesamiento en el sistema nervioso de los seres humanos son iguales para todos los de la misma especie (estructuralismo funcional), y similares para las demás especies humanas que habrá que intentar precisar. No obstante, la forma en que la percepción y procesamiento de la realidad va a producir la construcción cultural (económica, tecnológica, social y simbólica), sería distinta en los diferentes grupos humanos que conocemos. Así, cada grupo humano iría creando una estructura social y personal diferente, pues lo que en un principio es común, en su desarrollo se iria diversificando, pero siempre dentro de las limitaciones funcionales de tales estructuras comunes. Estos conceptos nos permiten comprobar la existencia de diferentes evoluciones culturales, basadas en la libre y diferente interpretación de los conceptos de naturaleza abstracta (p.e. individualidad social y/o personal, el tiempo, el espacio) (Hernando, 1999).

El Estructuralismo se fundamenta con la aceptación de unas estructuras o modelos genéricos, aparentemente no visibles, sobre el funcionamiento que rige la conducta humana (Lévi-Strauss, 1964; Jonson, 2000:121-123). En relación con la conducta deben existir unas reglas ocultas que usamos constantemente pero que no somos conscientes de ellas. Por tanto, las estructuras de percepción (sentidos) y procesamiento (cerebro) de la realidad serían similares en todos los grupos humanos, lo que implicaría que tenemos una forma básica, común a todos los pertenecientes a nuestra especie, de conocer e interpretar la realidad material del mundo en el que vivimos. El estructuralismo funcional que se propone intenta realizar una interpretación objetiva, pues para él, el sujeto que se analiza (seres humanos de la prehistoria o actuales) estaría determinado por esas caracteristicas comunes que encauzan las acciones humanas, mientras que el que lo estudia (antropólogo, arqueólogo, etc.) sólo intenta descubrir los mecanismos psicobiológicos comunes para entender la percepción de la realidad del grupo observado (Hernando, 1999). La clave estaría en conocer lo mejor posible esas caracteristicas evolutivas, psicobiológicas y sociales que van a conducir la conducta humana.

\subsection{Conceptos evolutivos}

La evolución es un proceso biológico donde los cambios genéticos y la selección natural del medio ambiente son sus principales mecanismos de producción. Actualmente, debido al mejor conocimiento de la genética y embriología humana se está desarrollando un concepto de evolución entendido como un fenómeno multifactorial de gran complejidad, donde los mecanismos de producción del cambio morfológico son consecuencia de la acción conjunta de diversos factores. Existen otros factores no siempre tenidos en cuenta para explicar la evolución de los órganos que van a lograr el desarrollo de nuestra conducta. Destacan las mutaciones de los genes estructurales (causantes de las estructuras anatómicas) y de los genes reguladores del proceso embriológico (genes controladores de la actividad, en tiempo y tasa de actuación de los genes estructurales). La mutación de los últimos sería la causa de las heterocronías, importantes alteraciones ontogénicas o del desarrollo embrionario, con cambios relativamente rápidos de diversas zonas corporales (evolución en mosaico) y de gran importancia evolutiva (Eldredge y Gould, 1972; Bermúdez de Castro y DomínguezRodrigo, 1992; Churchill, 1998; Bogin, 1999), sobre todo cuando afectan al cerebro por la repercusión conductual que pueden producir (Rakic, 1995).

La ontogénesis, en si misma, presenta un valor evolutivo que es necesario evaluar. Durante las primeras fases de formación embrionaria cualquier alteración estructural va a producir cambios morfológicos en cascada durante el resto de su desarrollo, no sólo como consecuencia del inicial cambio genético, sino como la adaptación de las sucesivas fases embriogénicas a estos cambios primarios (Andrew y Charles, 1996). Por tanto, cuando se observa un cambio evolutivo, lo que se ha producido es un cambio en la ontogenia de ese ser (Sinha, 1996). En referencia a la evolución neurológica la producción de cambios anatómicos relativamente rápidos por medio de las heterocronías y las características de la evolución en mosaico, dan lugar a un aumento cuantitativo de la corteza cerebral (Rakic, 1995), proporcionando un aumento de las capacidades cognitivas primarias de la especie humana evolucionada. Posteriormente, por medio de la estimulación sociocultural puede producirse un desarrollo cualitativo o aparición de nuevas capacidades cognitivas, es decir, de exaptaciones o cualidades cognitivas emergentes que aparecen después de los cambios anatómicos que los posibilitan por acciones específicas del medio ambiente, pero que no se crearon evolutivamente para realizar tal propiedad (Wilkins y Dumford, 1990; Gould, 1991; Skoyles, 1999). La transmisión de estas capacidades emergentes se realizaría por medio de la comunicación generacional (lenguaje), lo que pone en énfasis la importancia del nicho cultural humano (Bickerton, 2009) para el mantenimiento y evolución de la cultura humana. Por tanto, la evolución proporciona un ce- 
rebro funcional preparado para su adaptación al medio en el vaya a vivir, lo que dentro de las especies humanas ha tenido importantes diferencias de todo tipo (ambientales, sociales, simbólicas, socioculturales, etc.).

\subsection{Características neurológicas}

Las características neurológicas relacionadas con el origen y desarrollo de la conducta humana podemos agruparlas en dos grandes apartados:

1.2.1. Superficie funcional del córtex. La evolución dio lugar al desarrollo de un gran cerebro con un importante aumento de la corteza cerebral, donde las llamadas áreas de asociación terciarias son las responsables de nuestra actividad cognitiva superior, existiendo una relación inequivoca entre los cambios de conducta y el aumento de estas áreas asociativas del córtex cerebral (Luria, 1966; Bruner, 1984: 45-74; Kandel et al., 1997; Flórez et al., 1999; Gómez Pellón, 2005:155).

Existe una trascendental diferencia neurológica en las áreas terciarias del lóbulo frontal (zona anterior o prefrontal LPF) entre el ser humano y el resto de los primates (Semendeferi y Damasio, 2000). No sólo son mucho más amplias que los demás primates, sino que su estructura neurológica es menos densa, permitiendo que existan entre sus neuronas una interconectividad mucho mayor, produciendo una mayor y tardía mielinización (Semendeferi et al., 2002; Bufill y Carbonell, 2004). Estos estudios apuntan a que la superficie asociativa del córtex del LPF de los humanos tiene un carácter alométrico cuantitativo (aumento de la superficie funcional del córtex) y cualitativo (nuevas funciones cognitivas). Igualmente, se conoce que la extensión de las áreas terciarias del lóbulo frontal es proporcionalmente mayor que en los demás primates, debido a su mayor circunvolución y girificación (Rilling e Insel, 1999; Cela Conde, 2002).

1.2.2. Plasticidad del sistema nervioso. La inmadurez neurológica en el nacimiento es muy acusada en los humanos modernos, necesitando mucho más tiempo que otros primates para alcanzar el grado de funcionalidad óptimo. Durante la formación de la corteza cerebral en la embriogénesis se produce una delimitación imprecisa o protomapa de la distribución de las zonas que van a configurar las áreas corticales del futuro córtex. Será con el desarrollo postnatal (facilitado por su gran inmadurez), y en consonancia con la interacción de ese ser vivo con las características del medio ambiente y los constantes estímulos que se envían al cerebro, cuando se producirá definitivamente la organización funcional correspondiente a cada área (maduración neurológica) (Changeux, 1985: 233-237; Rakic, 1995; Jenkins et al., 1990; Just et al., 1996; Damasio, 1999: 110-111; Flórez et al., 1999: 24-27; Mora, 2001: 48-68). Así, las entradas de información sensorial procedentes del mundo exterior ad- quieren un papel determinante en el remodelamiento y organización definitiva de la corteza cerebral. De este modo, cualquier mapeo entre una localización cerebral y una capacidad cognitiva es una función variable entre dos niveles de descripción de un sistema dinámico, modulado por la demanda de la tarea y no una cartografía estática de la anatomía cerebral (Just et al., 1996).

La estructuración neurológica y mielinización justifican la existencia de un período crítico en el desarrollo de las capacidades cognitivas humanas, pasado el mismo es más difícil o casi imposible que éstas se desarrollen con las mismas características que dentro de él (Lenneberg, 1976: 208-212; Changeux, 1985: 271-272; Yuste, 1994; Flórez et al., 1999: 28; Mora, 2001: 69-88). El aumento de las áreas terciarias en superficie, su mayor interconectividad, la intensa inmadurez de nuestro cerebro al nacer, su gran plasticidad neurológica, la existencia de un periodo crítico para funciones cognitivas complejas, los procesos de lateralización funcional y la relación de su definitiva maduración funcional en relación con los estímulos externos, pone en manifiesto una visión del cerebro mucho más dinámica y dependiente de las características del medio ambiente en su definitiva configuración neurológica y funcional, de la cual va a depender la conducta de los seres humanos.

\subsection{Organización psicológica}

La Psicología cognitiva indica que las capacidades cognitivas son las responsables de la conducta. Uno de sus enfoques más aceptados corresponde al denominado Procesamiento de la Información, que se asocia a la concepción del ser humano como un sistema neurológico capaz de recibir, procesar, almacenar y recuperar la información que le llega a través de sus sentidos (Belinchón et al., 1992: 293295; González Labra, 1998: 27,34). Es fácil apreciar su buena relación con las características neurológicas anteriormente dichas. Sin embargo, el origen de estas capacidades cognitivas no es siempre el mismo, constituyendo un hecho fundamental que va a caracterizar nuestra conducta. Así, de una forma más didáctica que real, pueden establecerse dos grupos de capacidades cognitivas. Capacidades cognitivas primarias, consecuencia de todo aumento cuantitativo en las áreas de asociación del córtex. Son las que ofrece la evolución de una forma innata y se manifiestan con el simple desarrollo neurológico, pero con mayor o menor intensidad dependiendo de las características medioambientales. Resultan fundamentales para una conducta no simbólica, pues facilitan la adaptabilidad al medio en función de su propio nivel de capacidad y desarrollo. Entre ellas tenemos la memoria, funciones ejecutivas, atención, motivación, creatividad, razonamiento, percepción, etc. Como toda característica humana de base genética su manifestación fenotípica depende, en cierta medida, de las condiciones en las que se 
desarrollen dentro de un medio ambiente específico. Capacidades cognitivas emergentes o aumento cualitativo, su desarrollo se realiza mediante la influencia del medio ambiente cultural, dando lugar a un desarrollo cognitivo o la aparición de nuevas conductas complejas. Actualmente, se piensa que algunos de los procesos cognitivos de mayor trascendencia para la conducta humana (p. e: conciencia reflexiva, simbolismo elaborado) son propiedades emergentes del cerebro. De la unificación funcional de ciertas capacidades cognitivas más elementales (mecanismos de atención seriados, memoria a corto plazo, emotividad, etc.), se producirian nuevas y desconocidas propiedades cognitivas, entre las que se encuentra el simbolismo. Sin embargo, a partir de las capacidades elementales no puede intuirse tal propiedad (Edelman y Tononi, 2000; Searle 2000: 30; Mora: 2001: 142; Álvarez Munárriz, 2005: 25-31; Lewis-Williams, 2005; Rivera Arrizabalaga, 2009; Ardila y Ostrosky, 2008).

En función de las cualidades que ofrecen las capacidades primarias y dentro de un medio ambiente determinado, son las que aparecen a lo largo de nuestra evolución ligadas a la cultura que el ser humano es capaz de originar. La acción conjunta de todas ellas, más el resto de las capacidades cognitivas humanas, va a hacer posible la conducta humana moderna, caracterizada por una importante capacidad de elección y cambio, o flexibilidad en la adquisición y mejora de nuevas conductas. Igualmente, posibilita la abstracción y el simbolismo, fundamentales para crear una conducta simbólica con un poder adaptativo muy superior a los anteriores. El medio que nuestra sociedad tiene para transmitir sus avances culturales y todas las abstracciones mentales que la caracterizan (conceptos sobre la individualidad, el tiempo, el espacio, simbolismo, etc.) es el lenguaje. El cual, además de su valor de transmisión de ideas, sirve como elemento fundamental en la organización de nuestro pensamiento, pues facilita su estructuración simbólica sobre las abstracciones conocidas y aprendidas por medio del lenguaje. Tal función se realiza por medio de la interacción del lenguaje con el pensamiento, es decir, el aprendizaje de nuevos conceptos abstractos que van a facilitar nuevas pautas o posibilidades de realizar conductas más complejas o elaboradas, sería lo que en psicología se denomina como un desarrollo cognitivo. Por tanto, bajo la influencia de los estímulos externos y la adquisición e interiorización del simbolismo del lenguaje dentro del período crítico, se produce el desarrollo cognitivo humano marcado por los fenómenos de autoconciencia y demás procesos cognitivos, dando lugar a un importante cambio conductual, tanto en el simbolismo de sus actos como en el control de los mismos (Luria, 1966; Vygotsky, 1979; Bruner, 1984, 1988).

\subsection{Consideraciones sociológicas}

La conducta humana, y desde luego su lenguaje, son creaciones que las sociedades humanas generan a partir de las capacidades que la evolución les ha otorgado, y de la interrelación existente entre los diversos componentes de un grupo y las diversas poblaciones humanas entre sí. El ambiente cultural adecuado para la producción y perduración del desarrollo cognitivo humano hay que crearlo previamente, correspondiendo plenamente con el concepto de nicho cultural humano (Bickerton, 2009). Las condiciones ambientales y los aspectos socioculturales de la población son los factores que facilitan la motivación y la necesidad del desarrollo técnico y social, proceso en el que las capacidades cognitivas primarias tienen un papel fundamental (Henshilwood y Marean, 2003). En este sentido, los aspectos demográficos adquieren una importancia determinante, pues son los que más van a motivar los cambios conductuales (Shennan, 2001). Si los factores externos no adquieren unas características adecuadas, el desarrollo de las facultades cognitivas emergentes no llega a producirse o se realiza de forma anómala, dando lugar a importantes limitaciones cognitivas.

Naturalmente las condiciones ambientales de un lugar son comunes a todos los seres vivos que en él vivan, mientras que los aspectos socioculturales dependen de las propias características del grupo social y de la capacidad creativa que pueda manifestar con el objetivo de elaborar nuevos patrones culturales. Es preciso que existan diversos aspectos sociales para asegurar su desarrollo y mantenimiento. Primero, la existencia de uno de los factores emocionales que más nos interesa en estos momentos, como es la motivación o interés por realizar alguna función, lo que puede verse fácilmente en la necesidad de favorecer la comunicación, con el consecuente desarrollo del lenguaje, tanto intra como intergrupal. Segundo, todos los procesos anteriores sólo pueden desarrollarse en el seno de una sociedad estable. Estable en el sentido de poder asegurar la continuidad cultural a lo largo de sus generaciones, pues en poblaciones pequeñas y aisladas como las propias del Paleolítico Inferior y Medio, la continuidad del proceso no estaría asegurada. Tercero, la relación con otras poblaciones para crear la necesidad de avanzar en el desarrollo de la comunicación a través del lenguaje, así como del intercambio de nuevas abstracciones lingüísticas. Los tres aspectos deben darse a la vez, siendo éstos el verdadero motor de los cambios conductuales que se producen en las sociedades humanas, perdurando gracias a la estabilidad y desarrollo demográfico. La unión de estos factores facilita la motivación y la necesidad del progreso técnico y social, que podría conseguirse con el desarrollo de las capacidades cognitivas.

\subsection{Modelo conductual humano}

- La evolución ofrece capacidades funcionales desde el mismo nacimiento (capacidades cognitivas primarias). Existen otras capacidades que sólo se desarrollarían 
dentro de un medio ambiente adecuado (capacidades cognitivas exaptativas o emergentes).

- Las características psicobiológicas humanas indican la exigencia de un medio ambiente adecuado (que hay que crear) y de su aprendizaje, para su funcionalidad dentro de los parámetros modernos y simbólicos.

- Importancia de la sociedad para la motivación y diferenciación individual y social. El lenguaje es un proceso básico en la transmisión de los conceptos abstractos y simbólicos que van a facilitar el desarrollo de las capacidades cognitivas emergentes.

- En definitiva, la conducta no depende sólo de las capacidades cognitivas que se posean, sino de su propio desarrollo cognitivo, lo que a su vez depende de las caracteristicas medioambientales (sociales, demográficas, lingüisticas, tecnológicas, simbólicas, etc.).

- Al depender el desarrollo cognitivo (motor de todo cambio conductual) de las características culturales, sociales, demográficas y lingüísticas del medio en el que viva la sociedad en estudio, se explica el aspecto de mosaico cultural que apreciamos en las sociedades humanas durante el inicio del Paleolítico Superior (Straus, 2005). El desarrollo cultural no depende sólo de las capacidades cognitivas de cualquier especie humana, sino que es fundamental estar en un medio sociocultural adecuado que facilite su desarrollo cognitivo.

\section{CONDUCTA MODERNA O SIMBÓLICA}

Las condiciones cognitivas, sociales y medioambientales del inicio de Paleolítico Superior dieron lugar a un específico desarrollo cultural, que se manifestó en una conducta que desde entonces se ha considerado como moderna o simbólica. Sin embargo, aparece el problema de la propia definición de cultura moderna, pues mientras unos se limitan a presentar los aspectos de tecnología y tipología lítica como principal, y casi única, manifestación de tal modernidad, otros exigen mayor cambio en todas sus manifestaciones. Algunos autores reconocen una conducta moderna cuando está simbólicamente organizada, o es completamente simbólica (Henshilwood y Marean, 2003). Lo cierto es que la modernidad estaría muy ligada al nivel de simbolismo que la sustenta, siendo la cualidad más característica y de mayor trascendencia del Paleolítico Superior.

El simbolismo se define como la manifestación de un proceso cognitivo que otorga a determinados objetos y pinturas (elementos simbólicos), sonidos y gestos (lenguaje, música) o conductas (usos, ritos, costumbres), la representatividad de ciertas ideas, abstracciones o creencias, que la sociedad ha generado y aceptado en su conjunto. Puede que cierto simbolismo haya existido siempre a lo largo del proceso evolutivo de nuestro género, sería el caso de la exis- tencia de ciertas formas lingüísticas con un simbolismo primitivo (Rivera Arrizabalaga, 1998, 2003-2004, 2009). No obstante, para ser considerado como moderno se necesita de cierto desarrollo conceptual con una particular cadencia de producción, aunque su repercusión en el registro arqueológico ofrezca un aspecto heterogéneo o de mosaico cultural. En su estudio hay que tener la mayor objetividad posible, lo que puede intentarse utilizando el mayor número de ciencias relacionadas con la conducta humana, es decir, la metodología multidisciplinar utilizada en el anterior modelo de conducta humana, y no un enfoque meramente paleoantropológico y arqueológico. Si tenemos en cuenta las características del modelo conductual humano desarrollado en el anterior apartado, el simbolismo moderno presenta ciertas características:

- Es acumulativo, pues en su desarrollo utiliza anteriores conceptos (simbólicos o no) más elementales, pero imprescindibles para toda evolución simbólica.

- El simbolismo humano es un proceso cognitivo emergente. Pues de la unificación funcional de capacidades cognitivas primarias, más la obtención de conceptos abstractos de la naturaleza, se produciria un desarrollo cognitivo que desembocaría en la aparición de nuevas propiedades cognitivas, entre las que se encuentra el simbolismo.

- Su desarrollo precisa de unas características medioambientales determinadas (demográficas, socioeconómicas, tecnológicas, etc.). Por lo que su desarrollo histórico adquiere el aspecto de mosaico, tanto en los aspectos cognitivos como culturales.

- La evolución cultural y simbólica es un continuum que adquiere un aspecto de heterogeneidad, pues depende de diversos factores (capacidades y desarrollo cognitivo, existencia de un lenguaje previo, medioambiente sociocultural, etc.) que no siempre actúan con el mismo desarrollo. Este hecho sugiere la existencia de diversos grados de desarrollo intermedios, entre los niveles que podamos establecer.

- El simbolismo estaría íntimamente ligado al lenguaje, que sería la primera manifestación simbólica humana. La conducta lingüística permite la creación, mantenimiento y transmisión de todo proceso simbólico.

Las características de continuum y de manifestación cultural heterogénea indican el peligro de clasificar algunos yacimientos de ciertas culturas (que en algún momento de su desarrollo consiguieron generar conductas claramente simbólicas), sin conocer en qué fase de su particular desarrollo cultural hacia una conducta moderna se encuentran cada uno de ellos. Puede que tal yacimiento se encuentre en una fase precoz de desarrollo tecnológico (con cronología antigua), pero aún lejos de tener una conducta simbólica. 
Las características medioambientales determinadas indican que el simbolismo puede aparecer cuando estas sean las adecuadas, y no antes. Por tanto, es necesario establecer una representatividad poblacional y conductual adecuada, para evitar los posibles sesgos ocasionados por el estudio de poblaciones restringidas o culturas no representativas del total de la población, aunque luego todos entran en sus conclusiones. Así, el simbolismo del Chatelperroniense, que sólo se aprecia en unos pocos yacimientos, se asocia a todos los chatelperronienses $y$, por extensión, al Neandertal como una de sus características conductuales generales.

La modernidad o conducta simbólica estaría asociada a situaciones arqueológicas en las que se observe un aumento demográfico de las poblaciones que convivan en una determinada área geográfica, así como de cierta evolución socioeconómica, consecuencia de la existencia y desarrollo de las capacidades cognitivas que lo posibiliten. En su inicio, es fundamental crear las abstracciones que, por su carácter básico, van a constituir el armazón sobre el que se asentará todo el simbolismo y conducta moderna, como es el caso de la individualidad social y personal (elementos de diferenciación: adornos y pinturas), y su ubicación en el tiempo y el espacio (conductas con sentido temporal y espacial).

El concepto de individualidad (social y personal) siempre se produce en un medio social, por lo que dependería de las características de éste. Con este concepto iniciamos el reconocimiento e interiorización de la idea abstracta del yo-nosotros en relación con el concepto de tú-otros. La identificación, tanto individual como colectiva, de esta propiedad se basa en la noción de diferencia existente entre los individuos y grupos (Jenkins, 1996), que se traduce en la existencia universal de una palabra determinada para referirse a uno mismo o el yo (Elías, 1990). Para su producción es imprescindible una importante y continuada interacción social, tanto intra como intergrupal (Shennan, 2001), que genere continuamente situaciones de diferenciación de cualquier tipo (tecnológicas, políticas, religiosas, etc.) entre los individuos del mismo grupo, y de estos con otros grupos. La continuidad generacional de estas diferenciaciones facilitaría la formación conceptual de esta confrontación, hasta llegar a desarrollar un claro concepto de las ideas simbólicas del yo y los otros, es decir, de la individualidad social y personal. Su producción sería de tipo generacional, pues es preciso el recurso de muchas generaciones para desarrollar plenamente dichos conceptos. Los primeros avances, que la capacidad cognitiva humana debió desarrollar para crear un mundo simbólico como el actual, serían el inicio de la propia identificación social del grupo en contrapunto con la identificación de las demás poblaciones, es decir, a la creación del concepto de la individualidad social. Con posterioridad a su desarrollo se iniciarian los criterios de individualidad personal o diferencias particulares que surgen entre los elementos de un mismo grupo humano (Elías, 1990; Hernando, 1999).
A su vez, los conceptos del tiempo y del espacio, que no existen en la naturaleza como entidades físicas pero que se deducen de ella (Hernando, 1999), constituyen los componentes imprescindibles para la realización de toda conducta moderna, pues ubican a la persona o sociedad en un tiempo y espacio específico. El espacio se objetiva con la referencia a objetos fácilmente observables, inmóviles y permanentes, características constantes en el territorio donde se realiza 0 puede realizarse la acción (Elías, 1992; Hernando, 1999). El tiempo se realiza con la referencia de sucesos móviles de carácter no humano, pero con un tipo de movimiento recurrente, como son el paso del día a la noche, estaciones, fases lunares, etc. (Elías, 1992; Hernando, 1999).

Cuando se desarrollan con cierta complejidad estas abstracciones (individualidad, espacio y tiempo) es cuando otra importantísima y emergente propiedad cognitiva humana, como es la reflexividad de su pensamiento y conducta, que se traduce en una gran capacidad para la producción de rápidos cambios conductuales encaminados a solucionar nuevos problemas (flexibilidad conductual). Por tanto, el concepto de la individualidad personal, su ubicación en el espacio y el tiempo y la peculiar conducta que de ello se deriva, serían consecuencia del procesamiento de información ambiental específica, de las capacidades cognitivas evolucionadas y del lenguaje que pudieron desarrollar (Rivera Arrizabalaga, 2003-2004, 2004, 2009). Con la adquisición previa de estos conceptos es cuando comienzan a producirse los adornos, pinturas y herramientas creadas para identificar 0 diferenciar a sus productores, pues significa la creación y manifestación de la individualidad social y/o personal. También, las complejas conductas (almacenaje, caza estacional, distribución temporal del hábitat, etc.) denotan la adquisición y uso del concepto del tiempo, mientras que otras (control del área de aprovisionamiento, caza organizada, exportación de materias primas, relaciones sociales, etc.) indican el dominio del espacio. Su manifestación arqueológica se produce con un paulatino aumento hasta alcanzar, de una forma aparentemente rápida (Paleolítico Superior), un desarrollo lo suficientemente importante como para generar una conducta moderna o simbólica. Esta conducta puede aparecer en cada grupo de población, en un tiempo y lugar determinado, con formas conductuales diferentes y, por supuesto, con distinto nivel de desarrollo. Así, una característica fundamental del inicio de la conducta moderna sería la heterogeneidad cultural o de mosaico cultural (Straus, 2005).

\section{RECONOCIMIENTO ARQUEOLÓGICO DE LA CONDUCTA MODERNA}

No hay consenso unánime sobre el reconocimiento arqueológico de una conducta paleolítica considerada como moderna. Para diversos autores es suficiente con la existen- 
cia de una tecnología lítica predominantemente laminar como soporte de determinados útiles, como es el caso del posible origen del Auriñaciense en los Zagros (Kozlowski y Otte, 2000; Harrold y Otte, 2001; Olszewski y Dibble, 2006), aunque otros exigen la presencia añadida de tecnología ósea y de cierto simbolismo (Henshilwood y Marean, 2003). Hay que buscar rasgos conductuales especificos, con posibilidad de ser rastreados en el registro arqueológico, que indiquen el inicio del desarrollo de la modernidad, es decir, de una serie de conductas caracterizadas por cierta rapidez en su creación y variedad en sus formas (reflexividad y flexibilidad conductual), así como de la adquisición de los conceptos abstractos que simbolizar. Estos aspectos estarian en clara oposición con lo apreciado en los anteriores periodos paleolíticos, caracterizados por una importante estabilidad conductual y un simbolismo elemental con difícil relación con este tipo de abstracciones fundamentales. Así, no sería sólo el uso de una tecnología laminar lo más característico, que con cierta limitación ya se conoce en el Paleolítico Medio europeo (Boëda, 1990; Révillion y Tuffreau, 1994), sino la aparición relativamente rápida de nuevas conductas.

- Tecnología. Hay que apreciar la producción y rapidez de cambios tecnológicos (flexibilidad conductual) consecuencia de un proceso de razonamiento lógico (reflexividad), con el fin de mejorar la adaptabilidad al medio. En este sentido hay que valorar la mayor utilización de materias líticas de mejor calidad (sílex), a pesar de tener que transportarlo desde largas distancias (Fléblot-Augustins, 1993; Turq, 1993; Gamble, 2001), así como la adquisición de otras materias primas para la fabricación de útiles, como fueron los productos orgánicos (hueso, asta y marfil). Su uso obligaba a una remodelación de las herramientas líticas, apreciándose cierto paralelismo con el desarrollo tecnológico de estas materias primas (Camps, 1979; Beaure, 1999). Existen una serie de útiles líticos muy relacionados con el trabajo de las materias orgánicas, como son los buriles y raspadores (Semenov, 1957; Eiroa, et al., 1999), los cuales aumentan estadísticamente desde el inicio del Paleolítico Superior.

- Sociedad. Se observa una mayor flexibilidad en el desarrollo de conductas encaminadas a la creación y mantenimiento de estructuras sociales más complejas, creando redes sociales de comunicación, de intercambio y de apoyos permanentes. También se desarrollan usos del territorio y hábitat con características de mayor estructuración, complejidad y duración (Gamble, 2001). La relación social y comunicación experimenta un notable avance.

- Simbolismo. Tras un inicial desarrollo tecnológico se produce una mayor amplitud social y demográfica, apareciendo la necesidad de resaltar las diferencias de todo tipo (sociales, tecnológicas, de aptitud en tareas especificas, etc.) por medio de una nueva utilización, socialmente consensuada, de los medios a su alcance (adornos, pinturas, etc.). Estos adornos o elementos decorativos tienen un claro matiz diferenciador (pinturas y adornos de diverso tipo), pues representan o simbolizan cierto desarrollo de los conceptos abstractos sobre la individualidad social y/o personal. La individualidad personal estaría ligada al previo desarrollo de la individualidad social, pero siempre con un desarrollo posterior y condicionado a la estabilidad socioeconómica y cultural del grupo (Hernando 1999). Cuando el grupo alcance un mínimo de desarrollo económico y social que permita establecer distintas funciones sociales (tecnológicas, artísticas, religiosas, políticas, etc.), es cuando aparecerian las particularidades individuales representadas por elementos simbólicos encaminados a mostrar y mantener tales diferencias, lo cual sólo aparece con claridad en el Paleolítico Superior. Con posteridad, es cuando podemos encontrar los elementos artísticos, manifestaciones religiosas y funerarias.

- Economía. El mayor desarrollo que se alcanza en este campo se realiza por medio del desarrollo y uso de los conceptos del tiempo y del espacio aplicados a la economía de supervivencia, un ejemplo más de la flexibilidad y reflexividad conductual. En el inicio del Paleolítico Superior no se aprecian importantes diferencias con las formas de subsistencia del final del Paleolítico Medio (Pike-Tay y Knecht, 1993; Yravedra, 2002), es con cierta posterioridad cuando comienzan a verse conductas relacionadas con los conceptos espaciales y temporales encaminados a aumentar y conservar los recursos alimenticios (caza estacional, distribución espacial en función del movimiento de las manadas, almacenaje, etc.).

El desarrollo cognitivo que es capaz de producir una conducta moderna representa un continuum histórico, donde los avances culturales presentan cierto ordenamiento cronológico en su producción (tecnológico $\rightarrow$ social y demográfico $\rightarrow$ simbólico), pero con una importante heterogeneidad espacial en su desarrollo, tanto entre los Neandertales como en los HAM. Así, es característico encontrar diferentes logros culturales, lo que explica el aspecto de mosaico. En el caso de las culturas de transición ( $p$. e. Chatelperroniense y Auriñaciense arcaico) además de encontrar algún fósil guía (p.e. punta de Chatelperron o raspadores carenados), debe estar situada junto a una tecnología claramente laminar para ser atribuido a una cultura moderna como el Chatelperroniense o Auriñaciense. Parece lógico pensar que las características de plena 
modernidad (reflexividad y flexibilidad conductual, consecuencias de la adquisición de un pensamiento simbólico), además de la presencia de un fósil guía, debería de tener una tecnología ósea, pues es un índice claro de la existencia de estas dos cualidades (aceptar nuevas materias primas, crear nuevas formas de trabajo y estructurar herramientas más idóneas para su producción). La única presencia de tecnología laminar sería un mero indicio de una transición hacia la conducta moderna, pero no su plena adquisición. Así, en el continuum evolutivo de toda cultura pueden aparecer tecnologías laminares propias del Paleolítico Superior (p.e. Chatelperroniense), pero aún faltarian ciertos elementos tecnológicos (tecnología ósea), componentes simbólicos (adornos) y sociales (limitación en la amplitud de sus redes sociales y comerciales), que en cierta medida aparecerian posteriormente dentro de esa misma cultura.

\section{EL INICIO DE LA CONDUCTA MODERNA EN EUROPA}

En nuestro continente existe un problema añadido, como es la existencia de dos poblaciones humanas (neandertales y HAM) cuya relación biológica y capacidad cognitiva desconocemos. De estos humanos sabemos que tienen importantes diferencias de ADN (p.e. Lalueza Fox, 2005), su evolución se produjo en lugares lejanos (Europa y África), en diferentes medios ambientales y con un claro aislamiento geográfico entre ellos, indicando la coexistencia de dos formas evolutivas diferentes originadas a partir de un ancestro común con una antigüedad de unos 500.000 años. Sus procesos de evolución morfológica y neurológica siguieron caminos semejantes pero no idénticos (Klein, 1994; Noble y Davidson, 1996; Mithen, 1998; Mellars, 1999; Bruner, Manzi y Arsuaga, 2003; Wynn y Coolidge, 2004). Un axioma evolutivo indica que nunca evoluciones separadas han dado resultados exactamente iguales, por lo que sería más lógico pensar que las dos poblaciones tendrian unas capacidades cognitivas de configuración parecida, pero no exactamente iguales, aunque hay autores que afirman sus capacidades cognitivas sería muy parecidas (Zilhäo, 2008).

La teoría de la ruptura cultural afirma que los HAM ya habian desarrollado un comportamiento moderno cuando llegaron a Europa (p.e. Klein, 1994; Hublin, 1999; Mellars, 1999, 2005; Kozlowski y Otte, 2000; Gamble, 2001; Harrold y Otte, 2001; Stringer y Davies, 2001), puede que tal afirmación sea una consecuencia de las señales de modernidad que conocemos del registro arqueológico africano, producido con anterioridad al europeo (McBrearty y Brooks, 2000; D’Errico, 2003; Mellars, 2005). No obstante, en África se aprecian ciertas caracteristicas de escasez y desigualdad en su distribución temporal y espacial (Mellars, 1989, 1999;
Stringer y Gamble, 1996; Hublin, 1999; Henshilwood y Marean, 2003), aunque siempre puede decirse que son consecuencias de la falta de estudios extensivos. Sin embargo, tales conductas africanas no pueden justificar, por su simple existencia, la modernidad conductual de los HAM que llegaron a Europa por primera vez. Sobre todo, si pensamos que éstas pudieron ser oriundas de ciertas áreas del oeste de Asia (Kozlowski y Otte, 2000; Harrold y Otte, 2001; Olszewski y Dibble, 2006), donde no se han encontrado restos que indiquen tal modernidad, al menos tal y como se definió anteriormente. Los continuistas opinan que la conducta moderna fue una consecuencia de la evolución local de los neandertales, sin que existiera un cambio o interacción poblacional y social como motor para la producción de tan importantes cambios. Además, indican la producción simultánea e independiente de varios modelos como el Chatelperroniense y el Uluzziense (D'Errico et al., 1998, 2003; Zilhäo y D'Errico, 1999; Zilhäo, 2008), incluso de un Auriñaciense de transición (Cabrera et al., 2001).

\subsection{Conducta moderna entre los neandertales.}

La primera característica que encontramos en su registro arqueológico es una importante diversidad cultural durante el inicio del Paleolítico Superior, destacando las culturas con componentes simbólicos (Chatelperroniense, Uluzziense) sobre otras en las que sólo se observa cierta evolución tecnológica pero no simbólica (complejos centroeuropeos), o simplemente muestran la perduración del Musteriense. Esta diversidad da la impresión de cierta fragmentación social y cultural, así como una importante desigualdad del desarrollo cognitivo de los neandertales, si tenemos en cuenta el diferente nivel simbólico que conllevan dichas conductas (Rivera Arrizabalaga, 2008, 2008a). Diversos autores (D'Errico et al., 1998; D'Errico et al., 2003) atribuyen un alto simbolismo al Neandertal, tanto en el Paleolítico Medio como en el Superior. En el Musteriense interpretan ciertos conductas con un posible significado simbólico (enterramientos, uso de colorantes, ciertos adornos musterienses, etc.), siendo tal simbolismo ampliamente discutido (Stringer y Gamble, 1996). Su producción en este periodo implicaría la existencia de un alto desarrollo de sus capacidades cognitivas (reflexividad, flexibilidad conductual, creatividad, motivación, etc.), hecho que no se cumple en los otros aspectos arqueológicos (tecnológico, económico y social), pues durante el Musteriense se observa un importante éxtasis cultural (Mellars, 1999, 2005). Es difícil pensar en un importante desarrollo conductual parcial (simbolismo), cuando la adaptabilidad y supervivencia se basan más en el desarrollo de los otros dos aspectos (tecnológico y social) que, a su vez, dependen de las capacidades cognitivas que posibilitan el simbolismo y la reflexividad conductual. Ya se comentó que existe una importante relación entre la evolu- 
ción tecnológica, la amplitud demográfica y social, las capacidades cognitivas de cada especie y las características medioambientales con el desarrollo del simbolismo, de tal manera que hasta que las primeras no alcancen un determinado nivel, el simbolismo moderno no podrá aparecer (Rivera Arrizabalaga, 2003-2004, 2004, 2009).

Su cultura más desarrollada simbólicamente fue el Chatelperroniense, con una distribución geográfica limitada al centro-oeste y sur de Francia, y un menor desarrollo en el norte de la Península Ibérica, lo que indica una expansión limitada y con cierto aspecto regional (Pelegrin y Soressi, 2007). Sobre su origen se aprecia una importante relación tecnológica con el Musteriense de tradición Achelense $B$ (MTA B), pues en general suele aparecer donde previamente existía un Musteriense de este tipo o de denticulados, considerándose como una evolución del mismo hacia patrones propios del Paleolítico Superior (Bordes, 1984; Mellars, 1989; Baffier, 1999; Pelegrin y Soressi, 2007). Así, en niveles musterienses recientes (sobre el $45.000 \mathrm{bp}$ ) encontramos una evolución laminar y de piezas de dorso en progresivo aumento. La tecnología para la producción de puntas de Chatelperron se hace predominante, posiblemente por la gran utilidad de tales puntas (uso como cuchillo o puntas de lanzas), de tal manera que parecen ser el centro de toda la talla lítica, usando los subproductos de tallado como base para el resto de los útiles propios de esta cultura (Pelegrin y Soressi, 2007).

No cabe duda de que sus habilidades tecnológicas fueron altas, por lo menos similares a las de los HAM de la época (Coolidge y Wynn, 2004; Wynn y Coolidge, 2004; Mellars, 2005). La industria ósea asociada es sencilla y cuidadosamente tallada, aunque presenta una distribución geográfica muy limitada al encontrarse sólo en siete yacimientos franceses (Brassempouy, Châtelperron, Grotte du Renne, Laussel, Roc-de-Combe, Roche-au-Loup y Trou de la Chèvre) (D'Errico et al., 1998), y posiblemente en dos yacimientos españoles: La Güelga (Menéndez et al., 2005) y Labeko Koba (Arrizabalaga y Altuna, 2000) (tabla 1). Las materias primas se obtenían de las cercanías, pues las que tienen su origen en una distancia superior a los $16 \mathrm{Km}$ no superan el 6\% de la totalidad (Turq, 1993), aunque se nota un moderado aumento del sílex importado. En los aspectos sociales se aprecia un ligero aumento en sus manifestaciones (extensión de la red social, movilidad, estancias residenciales y obtención de materias primas) respecto a lo observado en el Musteriense, siendo un reflejo de una mayor organización social y de mejores estrategias logísticas (Baffier, 1999; Gamble, 2001). Los elementos simbólicos están muy restringidos geográficamente, pues los adornos sólo aparecen en seis yacimientos franceses: Cauna de Belvis, Grotte du Renne Châtelperron, Roc de Combe, Roche-au-Loup y Roche de Quinçay (D'Errico et al., 1998) (tabla 1). Hay que valorar un uso intensivo del ocre que suele cubrir de color todo el hábitat donde se encuentra, mientras que en el Musteriense se encuentra de una forma mucho más aislada (Baffier, 1999). Respecto de su economía en el periodo de transición no se observan cambios conductuales superiores a los comprobados a finales del Paleolítico Medio (Pike-Tay y Knecht, 1993; Yravedra, 2002), pues no se conocen actuaciones sociales con un marcado concepto logístico temporal y espacial. En muchos de sus yacimientos no se encuentran algunas de sus producciones líticas, o lo están en muy escasa proporción, dando aspecto de cierta pobreza tecnológica (Gamble, 2001). Este fenómeno donde más se aprecia es en la Península Ibérica (Morales Grajera, 1998), pues en la mayoría de sus yacimientos falta una tecnología laminar y ósea, lo que permite intuir la existencia de un Musteriense con puntas de Chatelperron más que de un pleno Chatelperroniense (Maroto et al., 2005). Pudiera ser que no hay que considerar al área arqueológica del Chatelperroniense como una verdadera extensión territorial de hábitat, sino sólo como una extensión de su potencial de abastecimiento (Gamble, 2001), o de influencia de los chatelperronienses a otros musterienses con menor desarrollo cognitivo y cercanos geográficamente. Incluso de influencia o relación con los HAM del inicio del Auriñaciense arcaico, lo que parece intuirse en la Península lbérica con la presencia de puntas de chatelperron en yacimientos considerados como Auriñacienses (L'Arbreda, Reclau Viver y El Castillo). El Uluzziense se conceptúa como una conducta moderna, aunque de forma más limitada. Se conoce el uso de la tecnología laminar con microlitos, y una incipiente utilización del hueso como materia prima. Se han encontrado conchas perforadas y colorantes amarillo (limonita) y rojo (ocre) en la cueva de Cavallo (Palma di Cesnola, 1993; D'Errico et al., 1998).

Es importante resaltar que salvo las áreas de extensión del Chatelperroniense y del Uluzziense, el resto del mundo del Neandertal carece en este periodo de muestras de cultura simbólica, por lo que hay que considerar que sólo algunos neandertales lograron un desarrollo cognitivo con características modernas (Rivera Arrizabalaga, 2008, 2008a).

\subsection{Conducta moderna atribuida a los HAM}

Sus yacimientos están repartidos por amplias zonas de Europa, en los que se aprecian importantes cambios tecnológicos, sociales y simbólicos (tabla 2). Desde sus primeras apariciones se comprueba una importante reflexividad y flexibilidad conductual. En la tecnología tenemos un notable desarrollo de la talla volumétrica de los núcleos como algo sistemático, para producir el soporte laminar de diversos útiles (raspadores carenados y en hocico, buriles, hojas auriñacienses, laminitas Dufour, etc.). Sin embargo, también es frecuente la presencia de elementos de sustrato o útiles propios del Musteriense (raederas, denticulados, muescas, etc.). La tecnología ósea es muy frecuente, lo que supone un uso generalizado como materia prima para la elaboración de úti- 
Tabla 1. Yacimientos de Catelperroniense y del Uluzziense con adornos y tecnología ósea en Francia, Italia y España

\begin{tabular}{|c|c|c|c|c|c|}
\hline Yacimiento & Nivel Cronología bp & CalPal (BP) 2007_HULU & Adornos & Tecnología ósea & Referencias \\
\hline \multirow{4}{*}{ 1. Grotte du Renne } & $\begin{array}{l}\text { VIII Chatelperroniense } \\
33860 \pm 250(\text { GrN-1742) }\end{array}$ & $39496 \pm 1017$ & \multirow{4}{*}{$\begin{array}{c}\text { Múltiples } \\
\text { dientes perforados } \\
\text { Aros marfil } \\
\text { Huesos ranurados }\end{array}$} & \multirow{4}{*}{$\begin{array}{c}\text { Punzones } \\
\text { Puntas } \\
\text { Subproductos óseos }\end{array}$} & \multirow{4}{*}{$\begin{array}{l}\text { D'Errico et al., } 1998 \\
\text { Zilhão, } 2007\end{array}$} \\
\hline & $\begin{array}{c}\text { IX Chatelperroniense } \\
45100 \pm 2800(0 \times A-3465)\end{array}$ & $49243 \pm 3376$ & & & \\
\hline & $\begin{array}{l}\text { Xab Chatelperroniense } \\
33820 \pm 720(0 \times A-3464)\end{array}$ & $38905 \pm 1486$ & & & \\
\hline & $\begin{array}{c}\text { Xc XI Musteriense } \\
33700 \pm 1400(\text { Ly-2164) }\end{array}$ & $38477 \pm 1897$ & & & \\
\hline 2. Cauna de Belvis & $\begin{array}{c}7 \text { Chatelperroniense } \\
35425 \pm 1140 \text { (AA-7390) }\end{array}$ & $40145 \pm 1267$ & $\begin{array}{c}2 \text { conchas sin trabajar } \\
\text { Turitella sp }\end{array}$ & & $\begin{array}{c}\text { D'Errico et al., } 1998 \\
\text { Zilhão, } 2007 \\
\text { Taborin, } 1993\end{array}$ \\
\hline \multirow{3}{*}{$\begin{array}{l}\text { 3. Grotte de Fées } \\
\text { Chatelperron }\end{array}$} & $\begin{array}{l}\text { B1.3H Chatelperroniense } \\
36250 \pm 750(0 \times A-13724)\end{array}$ & $40961 \pm 957$ & & \multirow{3}{*}{ Punzones Puntas } & \multirow{3}{*}{$\begin{array}{l}\text { D'Errico et al., } 1998 \\
\quad \text { Zilhão, } 2007\end{array}$} \\
\hline & $\begin{array}{c}\text { B4 ¿Auriñaciense? } \\
39780 \pm 390(0 x A-14319)\end{array}$ & $43627 \pm 598$ & $\begin{array}{l}2 \text { caninos felino } \\
\text { perforados }\end{array}$ & & \\
\hline & $\begin{array}{c}\text { B5 Chatelperroniense } \\
40650 \pm 600(0 \times A-13621)\end{array}$ & $44214 \pm 828$ & & & \\
\hline \multirow[b]{3}{*}{ 4. Roc-de-Combe } & $\begin{array}{c}8 \text { Chatelperroniense } \\
\text { K9 } 39540 \pm 970 \\
\text { (Gif-101264) }\end{array}$ & $43527 \pm 788$ & \multirow[b]{3}{*}{1 canino de lince } & \multirow{3}{*}{$\begin{array}{c}\text { Punzones. } \\
\text { Huesos marcados }\end{array}$} & \multirow{3}{*}{$\begin{array}{l}\text { D’Errico et al., } 1998 \\
\text { Mellars, } 2000 \\
\text { Zilhão, } 2007\end{array}$} \\
\hline & 9 ¿Auriñaciense? & & & & \\
\hline & $\begin{array}{c}10 \text { Chatelperroniense } \\
38000 \pm 2000 \\
(0 \times A-1443) \\
31000 \pm 750 \\
(0 \times A-1264)\end{array}$ & $\begin{array}{l}42283 \pm 1671 \\
35750 \pm 730\end{array}$ & & & \\
\hline 5. Roche-au-Loup & $5 b$ Chatelperroniense & $\begin{array}{c}>40000{ }^{14} \mathrm{C} \text { convencional } \\
\text { Gif- } 2414\end{array}$ & $\begin{array}{c}2 \text { incisivos (bovino, reno) } \\
\text { Huesos marcados } \\
\text { ¿Aros marfil? }\end{array}$ & $\begin{array}{l}\text { Punzones } \\
\text { Puntas }\end{array}$ & $\begin{array}{l}\text { D'Errico et al., } 1998 \\
\text { Zilhão, } 2007\end{array}$ \\
\hline \multirow{3}{*}{$\begin{array}{l}\text { 6. La Grande Roche, } \\
\text { à Quinçay }\end{array}$} & Egc. y En. Chatelpe. arcaico. & & & & \multirow{3}{*}{$\begin{array}{l}\text { D'Errico et al., } 1998 \\
\text { Zilhão, } 2007 \\
\text { Lévêque, } 1993 \\
\text { White, } 1993\end{array}$} \\
\hline & $\begin{array}{l}\text { Em. Chatelperroniense } \\
\text { evolucionado. } 33000 \mathrm{bp}\end{array}$ & & $\begin{array}{l}6 \text { dientes perforados (zorro, } \\
\text { lobo, ciervo) }\end{array}$ & & \\
\hline & Ej. Chatelpe. regresivo. & & & & \\
\hline $\begin{array}{l}\text { 7. Abri Dubalen } \\
\text { Brassempouy }\end{array}$ & $\begin{array}{c}\text { EBC2 Chatelperroniense } \\
36130 \pm 690 . \text { (GifA-101045) }\end{array}$ & $40863 \pm 966$ & & Subproductos óseos & $\begin{array}{l}\text { D'Errico et al., } 1998 \\
\text { Zilhão, } 2007\end{array}$ \\
\hline 8. Laussel & Chatelperroniense & & & $\begin{array}{l}\text { Punzones Puntas } \\
\text { Subproductos }\end{array}$ & D'Errico et al., 1998 \\
\hline $\begin{array}{l}\text { 9. Trou de la } \\
\text { Chèvre }\end{array}$ & 18-15 Chatelperroniense & & & Punzones Puntas & D'Errico et al., 1998 \\
\hline 10. La Fabbrica & 2 Uluzziense & & & $\begin{array}{l}\text { Punzones y fragmentos de } \\
\text { gruesas puntas }\end{array}$ & $\begin{array}{l}\text { Palma di Cesnola, } 1993 \\
\text { Kuhn y Bietti, } 2000\end{array}$ \\
\hline 11. Castelvicita & $\begin{array}{c}\text { Rpi Uluzziense } \\
33300 \pm 430 \\
{ }^{14} \mathrm{C} \text { convencional }\end{array}$ & $37880 \pm 909$ & & $\begin{array}{l}\text { Punzones y fragmentos } \\
\text { de gruesas puntas }\end{array}$ & $\begin{array}{l}\text { Palma di Cesnola, } 1993 \\
\text { Kuhn y Bietti, } 2000\end{array}$ \\
\hline 12. Grotta de Cavallo & $\begin{array}{l}\text { Ei-Eii Uluzziense } \\
>31000 \\
{ }^{14} \mathrm{C} \text { convencional }\end{array}$ & & Conchas perforadas & $\begin{array}{l}\text { Punzones y fragmentos de } \\
\text { gruesas puntas }\end{array}$ & $\begin{array}{l}\text { Palma di Cesnola, } 1993 \\
\text { Kuhn y Bietti, } 2000\end{array}$ \\
\hline 13. La Güelga & $\begin{array}{l}\text { N. 14A (zona D exterior): } \\
\text { AMS hueso 29550 } 310 \\
\text { Beta-172345) } \\
\text { Nivel 4B (zona D exterior): } \\
\text { AMS hueso 29.020 } 260 \\
\text { (Beta-196766) }\end{array}$ & $\begin{array}{l}33853 \pm 357 \\
33.502 \pm 374\end{array}$ & & $\begin{array}{l}\text { Láminas musterienses. } \\
2 \text { puntas de Chatelperron. } \\
\text { Tecnología ósea } \\
\text { (4B- zona D exterior) }\end{array}$ & Menéndez et al., 2005 \\
\hline 14. Labeko Koba & $\begin{array}{l}\text { Nivel IX inf: } 34215 \pm 1265 \\
\text { (Ua-3324) AMS hueso } \\
\text { N. IX centro: } 29750 \pm 740 \\
\text { (Ua-3325) AMS hueso }\end{array}$ & $\begin{array}{l}38906 \pm 1701 \\
33926 \pm 649\end{array}$ & & $\begin{array}{c}\text { Lascas. } 3 \text { puntas } \\
\text { de Chatelperron } \\
\text { Tecnología ósea y laminar }\end{array}$ & $\begin{array}{c}\text { Arrizabalaga } \\
\text { y Altuna, } 2000\end{array}$ \\
\hline
\end{tabular}

les especificos (punzones, perforadores, varillas perforadas y puntas), la producción de herramientas para el retoque de la talla lítica y la configuración de adornos (Gamble, 2001). Destacan las puntas de azagayas óseas en diversos yacimientos, indicando su uso como armas arrojadizas. También, observamos un cambio sustancial en las materias primas utilizadas en la industria lítica, pues se prefiere el uso de piedras muy duras y de mejor calidad para la fabricación de los útiles laminares, como es el caso del sílex (Gamble, 2001). Su importación se incrementa en cantidad y lejanía, supe- 
Tabla 2. Yacimientos europeos con Auriñaciense arcaico

\begin{tabular}{|c|c|c|c|c|}
\hline Yacimiento & Estratigrafía & Cronología & Tecnología & Referencias \\
\hline $\begin{array}{l}\text { L'Arbreda } \\
\text { Gerona (España) }\end{array}$ & $\begin{array}{l}\text { Nivel H: Auriñaciense ar. } \\
\text { Nivel I: Musteriense }\end{array}$ & $\begin{array}{l}\text { Nivel H: C-14 AMS } \\
38.700 \pm 1200 \text { BP (AA.3782) } \\
\text { Nivel I } 41.400 \pm 1.600 \\
\text { BP (AA 3778) }\end{array}$ & $\begin{array}{c}\text { Nivel H: Tecnologia laminar y ósea. } \\
\text { Silex importado } \\
\text { Ocre, conchas } \\
\text { Nivel I: } 4 \text { puntas Chatelperron }\end{array}$ & $\begin{array}{c}\text { Straus, } 1996 \\
\text { D'Errico et al., } 1998\end{array}$ \\
\hline $\begin{array}{l}2 \text { Abrí Romaní } \\
\text { Barcelona (España) }\end{array}$ & $\begin{array}{l}\text { Nivel 2: Auriñaciense ar. } \\
\text { Nivel 3: Estéril } \\
\text { Nivel 4: Musteriense }\end{array}$ & $\begin{array}{c}\text { Nivel 2: C-14 AMS } \\
37.900 \pm 1000 \text { BP } \\
\text { (AA-8037B) }\end{array}$ & $\begin{array}{l}\text { Nivel 2: Tecnología laminar } \\
\text { y ósea. Silex importado } \\
\text { Ocre. conchas }\end{array}$ & $\begin{array}{l}\text { Carbonell et al., } 1996 \\
\text { Straus, } 1996\end{array}$ \\
\hline $\begin{array}{l}3 \text { Reclau Viver } \\
\text { Gerona (España) }\end{array}$ & $\begin{array}{l}\text { Nivel B: Auriñaciense I } \\
\text { Nivel A: Auriñaciense ar. }\end{array}$ & $\begin{array}{l}\text { Nivel A C-14 AMS } \\
40.000 \pm 1400 \mathrm{BP} \\
(0 \times A-3727\end{array}$ & $\begin{array}{l}\text { Nivel A: Tecnología laminar y ósea. } \\
\text { Silex importado } \\
3 \text { puntas Chatelperron aisladas }\end{array}$ & $\begin{array}{c}\text { Straus, } 1996 \\
\text { D'Errico et al., } 1998\end{array}$ \\
\hline $\begin{array}{c}4 \text { El Castillo } \\
\text { Cantabria (España) }\end{array}$ & $\begin{array}{l}\text { Nivel 18c: Auriñaciense ar. } \\
\text { Nivel: } 19 \text { Estéril } \\
\text { Nivel 20: Musteriense }\end{array}$ & $\begin{array}{l}\text { Nivel 18c: C-14 AMS } \\
40.700 \pm 1600 \mathrm{BP} \\
(0 \times A-2475)\end{array}$ & $\begin{array}{c}\text { Nivel 18c: Tecnologia laminar y ósea. } \\
\text { Cuarcita local } \\
1 \text { punta Chatelperron }\end{array}$ & $\begin{array}{c}\text { Straus, } 1996 \\
\text { Cabrera et al., } 2001\end{array}$ \\
\hline $\begin{array}{l}5 \text { Morín } \\
\text { Cantabria (España) }\end{array}$ & $\begin{array}{l}\text { Nivel } 8 \text { y 9: Auriñacien ar. } \\
\text { Nivel 10: Chatelperroniense } \\
\text { Nivel 11: Musteriense }\end{array}$ & $\begin{array}{c}\text { Nivel } 8 \text { C-14 AMS } \\
36.590 \pm 770 \text { BP } \\
\text { (GifA } 96263\end{array}$ & $\begin{array}{c}\text { Nivel 8: Tecnologia laminar y ósea. } \\
\text { Hojitas Dufour } \\
\text { Azagaya base hendida }\end{array}$ & Maillo et al., 2001 \\
\hline $\begin{array}{c}6 \text { La Viña } \\
\text { Asturias (España) }\end{array}$ & $\begin{array}{l}\text { N. XIII: Auriñaciense ar. } \\
\text { Nivel XIII inf: Auriña. ar. } \\
\text { Nivel XIII basal: Musteriense }\end{array}$ & $\begin{array}{c}\text { Nivel XIII inf: C-14 36.500 } \pm 750 \\
\text { BP (Ly-6390) }\end{array}$ & $\begin{array}{l}\text { Nivel XIII inf: Tecnología } \\
\text { laminar y ósea } \\
\text { Grabados parietales }\end{array}$ & Fortea Pérez, 1999 \\
\hline $\begin{array}{c}7 \text { Isturitz } \\
\text { Saint-Martin d'Arberoue } \\
\text { (Francia) }\end{array}$ & $\begin{array}{l}\text { Nivel C4d base: } \\
\text { Protoauriñaciense }\end{array}$ & $\begin{array}{l}\text { Nivel C4d base: } \\
\text { C-14 AMS } \\
36.550 \pm 610 \text { BP } \\
\text { (GifA-98238) }\end{array}$ & $\begin{array}{c}\text { Nivel C4d base: Tecnología laminar } \\
\text { y ósea. Silex }\end{array}$ & $\begin{array}{c}\text { Esparza, } 1995 \\
\text { Zilhão y D'Errico, } 1999\end{array}$ \\
\hline $\begin{array}{l}8 \text { G. Fumane } \\
\text { Verona (Italia) }\end{array}$ & $\begin{array}{l}\text { Nivel A 3-2-1: Auriñaci. ar. } \\
\text { Nivel A 4: Indeterminado } \\
\text { Nivel A 13-5: Musteriense }\end{array}$ & $\begin{array}{c}\text { Nivel A 3-2-1: C-14 AMS. } \\
\text { 36.500 } \pm 600 \mathrm{BP} \\
\text { (UtC.2048) }\end{array}$ & $\begin{array}{c}\text { Nivel A 3-2-1: Tecnología laminar } \\
\text { y ósea. Silex. Ccolgantes dientes } \\
\text { de ciervo }\end{array}$ & $\begin{array}{l}\text { Broglio et al., } 1996 \\
\text { Straus, } 1996\end{array}$ \\
\hline $\begin{array}{l}9 \text { Abri Mochi } \\
\text { Riparo Mochi (Italia) }\end{array}$ & $\begin{array}{l}\text { Nivel G: Auriñaciense ar. } \\
\text { Nivel H: Mezcla } \\
\text { Nivel I: Musteriense }\end{array}$ & $\begin{array}{l}\text { Nivel G: C-14 AMS } \\
35.700 \pm 850 \mathrm{BP} \\
(0 \times A-3591)\end{array}$ & $\begin{array}{c}\text { Nvel G: Tecnología laminar y ósea. } \\
\text { Silex. Colgantes, conchas, } \\
\text { dientes y huesos }\end{array}$ & Kuhn y Stiner, 1998 \\
\hline $\begin{array}{l}10 \text { Trou Magrite } \\
\text { Namur (Bélgica) }\end{array}$ & $\begin{array}{l}\text { Nivel 3: Auriñaciense ar. } \\
\text { Nivel 3/4: Estéril. } \\
\text { Nivel 4: Musteriense }\end{array}$ & $\begin{array}{l}\text { Nivel 3: C-14 AMS } \\
\text { 41.300 } \pm 1690 \text { BP } \\
\text { (CAMS-10352) }\end{array}$ & $\begin{array}{l}\text { Nivel 3: Tecnología laminar. Caliza local. } \\
\text { Silex importado }\end{array}$ & $\begin{array}{l}\text { Otte y Straus, } 1995 \\
\text { Straus, } 1996\end{array}$ \\
\hline $\begin{array}{l}11 \text { Willendorf II } \\
\text { Krems (Austria) }\end{array}$ & $\begin{array}{l}\text { Nivel 3: Auriñaciense ar. } \\
\text { Nivel 1-2: Paleolítico superior } \\
\text { indeterminado }\end{array}$ & $\begin{array}{c}\text { Nivel } 3 \mathrm{C}-14 \\
38.880 \pm 1530 \mathrm{BP} \\
(\mathrm{GrN}-17805)\end{array}$ & $\begin{array}{l}\text { Nivel 3: Tecnología laminar } \\
\text { y ósea Sílex }\end{array}$ & Djindjian et al., 1999 \\
\hline $\begin{array}{l}12 \text { Geissenklösterle } \\
\text { Achtal (Alemania) }\end{array}$ & $\begin{array}{l}\text { Nivel I-II: Auriñaciense } \\
\text { Nivel III: Auriñaciense ar. } \\
\text { Nivel III/IV: Estéril. } \\
\text { Nivel IV: Musteriense }\end{array}$ & $\begin{array}{l}\text { Nivel III: } \\
\text { C-14 AMS } \\
37.800 \pm 550 \text { BP } \\
\text { (ETH-8267) }\end{array}$ & $\begin{array}{l}\text { Nivel III: Tecnologia laminar. } \\
\text { Raspadores, buriles. Silex } \\
\text { Nivel II: Tecnología ósea. Cuentas }\end{array}$ & Conard y Bolus, 2003 \\
\hline $\begin{array}{l}13 \text { Istallöskö } \\
\text { Szilvasvarad (Hungría) }\end{array}$ & $\begin{array}{l}\text { Nivel 5: Auriñaciense ar. } \\
\text { Nivel 6: Estéril } \\
\text { Nivel } 7 \text { Inf: Auriñacie. ar. }\end{array}$ & $\begin{array}{c}\text { Nivel } 7 \text { inf: } \\
\text { C-14 } 44.300 \pm 1900 \text { BP } \\
\text { (GrN-4659) }\end{array}$ & $\begin{array}{c}\text { Nivel } 7 \text { inf: } \\
\text { Tecnología laminar y ósea } \\
\text { Silex importado }\end{array}$ & $\begin{array}{l}\text { Straus, } 1996 \\
\text { Adams, } 1998\end{array}$ \\
\hline $\begin{array}{l}14 \text { Bacho Kiro } \\
\text { Drianovo (Bulgaria) }\end{array}$ & $\begin{array}{l}\text { Nivel 4-11: Auriñaciense ar. } \\
\text { Nivel 12-14: Musteriense }\end{array}$ & $\begin{array}{l}\text { Nivel } 11 \\
\text { C-14 AMS hueso } \\
38.500 \pm 1700 \text { BP } \\
\text { (0xA-3183) }\end{array}$ & $\begin{array}{l}\text { Nivel 11: Tecnología laminar. } \\
\text { Silex importado } \\
\text { Nivel 9: Tecnología ósea } \\
\text { Dientes perforados }\end{array}$ & $\begin{array}{c}\text { Straus, } 1996 \\
\text { Djindjian et al., } 1999\end{array}$ \\
\hline $\begin{array}{l}15 \text { Temnata } \\
\text { Karlukovo (Bulgaria) }\end{array}$ & $\begin{array}{l}\text { Nivel 4: Auriñaciense ar. } \\
\text { Nivel 5: Estéril. } \\
\text { Nivel 6: Musteriense }\end{array}$ & $\begin{array}{l}\text { Nivel } 4 \text { (TD-I): } \\
\text { C-14 AMS } \\
39.100 \pm 1800 \text { BP } \\
\text { (0xA-5169) }\end{array}$ & $\begin{array}{l}\text { Nivel } 4 \text { (TD-I): } \\
\text { Tecnología laminar } \\
\text { Sílex más local }\end{array}$ & Ginter et al., 1996 \\
\hline
\end{tabular}

rando claramente lo visto entre los neandertales, tanto del Musteriense como en la transición (Fléblot-Augustins, 1993; Turq, 1993). En la Cornisa Cantábrica (El Castillo y La Viña) continúan usando la cuarcita local, pues contiene un grano muy fino que permite obtener útiles de gran calidad (Cabrera et al., 2001).

Sus comunidades parecen estar más desarrolladas, con asentamientos mejor estructurados y de uso más prolongado que el observado en el Paleolítico Medio. En los aspectos sociales se aprecia una mayor complejidad tecnológica y sociocultural con una importante extensión y generalización, lo que facilitará el desarrollo poblacional. Las relaciones regionales se incrementan produciéndose un aumento de la población, junto con la extensión y la eficacia de redes de alianza, que unen zonas de altos recursos con otras de menor cantidad, en busca de posibles equilibrios económicos (Gam- 
ble, 2001). La elección del hábitat en el inicio del Auriñaciense ofrece unas características importantes, pues se observa una peculiar forma de distribución geográfica. En la estratigrafía de sus primeros yacimientos (tabla 2) vemos que algunos de ellos no hay niveles del Musteriense ni del Chatelperroniense (Reclau Viver, La Viña, Willendorf II, IstaIlöskö). Otros, están claramente separados por un nivel estéril del estrato inferior Musteriense (Abrí Romaní, El Castillo, Trou Magrite, Geissenklösterle y Temnata). En los restantes el Auriñaciense arcaico se sitúa directamente sobre el Musteriense o Chatelperroniense, pero hay una gran diferenciación cultural (Bacho Kiro) o existe entre ellos un estrato de dudosa interpretación, como mezcla o indiferenciado (L'Arbreda, Morín, Isturitz, Grotta Fumane y Abri Mochi). De estos 15 yacimientos parece desprenderse la idea de que el Auriñaciense arcaico en muchos casos no tiene una relación directa con el Musteriense o Chatelperroniense, pues sólo un 40\% del total está en contacto directo con ellos, y aún así la mayoría de estos yacimientos tienen una diferenciación cultural, una dudosa evolución cultural local o parece existir una mezcla de niveles. Parece que la expansión Auriñaciense buscaba lugares vacíos que repoblar (Stringer y Davies, 2001), más que una competitividad directa.

El simbolismo está bien representado, pues tenemos una buena serie de objetos que así lo indican, apareciendo con un carácter relativamente brusco, si tenemos en cuenta los antecedentes del periodo anterior. Destacan los adornos personales, como cuentas de hueso y marfil, dientes perforados, conchas marinas importadas principalmente desde la costa del Atlántico a cientos de Km (Taborin, 1993), primeros huesos con muescas o grabados (White, 1993). Estos adornos están muy extendidos geográficamente, pues prácticamente se encuentran repartidos por toda la Europa habitable del periodo Auriñaciense, conociéndose en 98 yacimientos (Vanhaeren y D'Errico, 2006), lo que indica una importante diferencia estadística con los yacimientos con adornos de los neandertales (sólo seis).

La economía se basa en la caza y la recolección, pero observamos una tendencia hacia una mayor amplitud en el uso de recursos, con una logística que la haría más efectiva (Stiner et al., 1999), aunque en un principio no observamos grandes cambios en los que se precisa un mayor control de los conceptos temporales y espaciales (Pike-Tay y Knecht, 1993; Yravedra, 2002). En general, estos yacimientos ofrecen aspectos de cierta sincronía temporal e importante precocidad cultural en la mayoría de los yacimientos de este periodo, dando la impresión de un desarrollo creativo pujante y generalizado. Todo indica una gran reflexividad y flexibilidad conductual generalizada y mantenida en el tiempo, pero con diferente desarrollo que el visto entre los neandertales, aunque si de formas parecidas por tener comunes patrones psicobiológicos propios de un antepasado común (Rivera Arrizabalaga, 2008, 2008a).

\subsection{Modernización conductual en Europa}

El inicio de la conducta moderna entre las poblaciones europeas del final del Paleolítico Medio fue la consecuencia de dos complejos procesos. Primero, la climatología adversa del periodo, pues la producción de cambios relativamente bruscos e intensos en las temperaturas medias (Rivera Arrizabalaga, 2004a) originaría la necesidad de nuevas soluciones a determinados problemas de supervivencia, entre los que destacarian los movimientos poblacionales. No obstante, debe considerarse como coadyuvante y no como causa única y determinante, pues similares cambios climáticos debieron de producirse en Europa durante la larga existencia del Neandertal, lo que no fue causa de una evolución cultural moderna. Segundo, la presión demográfica y social entre los diferentes tipos de poblaciones (neandertales y HAM), entre los distintos grupos pertenecientes a un mismo tipo de población y entre los elementos de cada grupo humano, pudieron constituir la motivación que incitara a crear un específico y nuevo ambiente sociocultural. Su mismo medio de vida (cazadores-recolectores con el nivel de desarrollo del final del Musteriense, más oportunista que organizado en el tiempo y en el espacio) les obligaba a mantener grandes áreas logísticas para sobrevivir. Aunque pudieran tener algunos objetivos de abastecimiento diferentes, a veces sus intereses se entrecruzarian, lo que les obligaría a excluirse, competir o a relacionarse.

La conducta simbólica de características modernas es posterior al desarrollo cognitivo, tecnológico, social y demográfico que lo posibilita. Su aparición se produciría dentro del continuum que representa el desarrollo cultural de las poblaciones humanas. Los neandertales a finales del Paleolítico Medio tuvieron cierto desarrollo tecnológico (industrias laminares) en diversas áreas geográficas de Europa (Szeletiense, Chatelperroniense tecnológico, complejo Lincombien-Ranisien-Jerzmanowiciense, etc.), pero la moderna industria ósea y los adornos, como exponente más representativo de un simbolismo elaborado, fue más reciente.

Del Chatelperroniense conocemos unos 125 yacimientos en Francia y la Península Ibérica (Demars, 1996; D'Errico et al., 1998), lo que sin duda supone una adecuada muestra poblacional de tal tecnología. No obstante, el carácter moderno de su conducta (reflexividad y flexibilidad manifestados por la tecnología ósea y la creación se adornos) es muy restringido, pues los adornos quedan limitados a seis yacimientos, la mayoría de ellos situados en la periferia del núcleo principal de yacimientos chatelperronienses (centro y SO de Francia). Su distribución geográfica puede relacionarse con la evolución simbólica de los HAM, pues los yacimientos de Châtelperron, Grotte du Renne y Roche-au-Loup se sitúan a $450 \mathrm{Km}$ de los yacimientos Auriñacienses de Alemania (Vogelherd o Geisseklöosterle), precisamente con parecidos adornos (Harald, 2003; Mellars et al., 2007). Por su parte, Cauna 
de Belvis se sitúa muy cerca del Mediterráneo donde los protoauriñacienses usaban frecuentemente las conchas como adornos (Mellars, 2005). Roc de Combe y Roche de Quinçay, yacimientos con adornos, se encuentran en el núcleo de mayor densidad poblacional de los neandertales (tabla 1).

- El yacimiento de Grotte du Renne es el más importante de todos. Conocemos muchas dataciones (33$35.000 \mathrm{BP}$ ) y adornos en todos sus niveles, pero salvo una de 45.100 BP que, por su excesiva antigüedad, parece más una intromisión de un nivel Musteriense inferior (Mellars, 1999; Bar-Yosef, 2006), las demás son totalmente coetáneas con los HAM (Harald, 2003; Mellars et al., 2007). En todos los niveles chatelperronienses encontramos adornos y tecnología ósea, pero su situación geográfica es muy marginal del territorio poblado por los chatelperronienses, y relativamente cercana a los yacimientos auriñacienses.

- La Roche-au-Loup está muy cerca del anterior, por lo que no sería raro que siguiera su mismo desarrollo. Su datación es convencional $\left({ }^{14} \mathrm{C}\right)$, dando un impreciso > 40000 bp.

- En la Grotte des Fées en Châtelperron conocemos dos caninos en el discutido nivel B4. Este estrato puede corresponder a un Auriñaciense interestratificado entre dos Chatelperronienses (Mellars et al., 2007), o un Chatelperroniense pero con alteraciones postdeposicionales (Zilhäo et al., 2006), generando dudas sobre su autoría (39.780 \pm 390 BP). Como los adornos están precisamente en los niveles dudosos, pueden tener el mismo origen que la tecnología lítica considerada como consecuencia de alteraciones estratigráficas. Por otro lado, el canino de ciervo rojo perforado es igual al visto en Grotte du Renne. El de zorro está perforado según la técnica del Auriñaciense (White, 1993, Zilhão et al., 2008), diferente a lo visto en Grotte du Renne y Quinçay (Mellars et al., 2007). Esta discusión e incertidumbre en su atribución cultural ofrece un aspecto de poca fiabilidad al yacimiento, al menos como dato sobre la antigüedad del simbolismo chatelperroniense. Si está mal reflejada su estratigrafía, los datos de este nivel serán tan dudosos para la tecnología lítica como para los adornos.

- En Roc de Combe, igual que en el caso anterior, existe otro problema de interestratificación entre un posible nivel Auriñaciense (9) y dos adyacentes Chatelperronienses (8 y 10). La comprobación de alteraciones estratigráficas que pone en duda la correcta ubicación temporal y cultural de la industria lítica encontrada en estos estratos alterados (Bordes, 2003), afectarían de igual modo a los adornos encontrados (un sólo canino de lince perforado), por lo que su dudosa cronología y autoría tampoco nos ofrecen seguridad sobre la antigüedad del inicio del simbolismo personal Chatelperroniense. Hay que resaltar que, a pesar de estar rodeado de numerosos yacimientos chatelperronienses, es el único que contiene adornos, y sólo dos más (Laussel y Le Trou de la Chèvre) contienen tecnología ósea.

- El yacimiento de Roche de Quinçay es uno de los dos lugares (junto con Grotte de Renne) donde hay testimonios tecnológicos sobre la fabricación de estos adornos. Los adornos se encontraron en un nivel de Chatelperroniense evolucionado, situándolos sobre el 33.000 BP (White, 1993; Granger y Lévêque, 1997). Se sitúa en zonas chatelperronienses marginales.

- En Cauna de Belvis tenemos una sola concha sin trabajar que, al estar cerca del mar, es poco significativo sobre su posible uso como adorno (35425 \pm 1140 BP).

Parecida representación tiene la industria ósea, pues es igualmente escasa con sólo siete yacimientos en Francia, de los cuales cinco coinciden con los anteriores (tabla1). Con las razonables dudas que ofrecen las dataciones en los yacimientos de controvertida estratigrafía y los pocos datos que disponemos, no es raro pensar que los adornos entre los neandertales no son más antiguos del $36.000 \mathrm{BP}$, siendo contemporáneos del simbolismo Auriñaciense. Esta situación cronológica apunta la posibilidad de una relación motivacional y creativa entre ambas poblaciones, con sus correspondientes consecuencias simbólicas. Podría pensarse que muchos de los posibles adornos o tecnología ósea de este período se han destruido por las características fisicoquímicas del terreno, pero el registro de los adornos auriñacienses, aunque en lugares y épocas más amplias, indican su existencia en 98 yacimientos (Vanhaeren y D'Errico, 2006) con similares caracteristicas del medio ambiente, lo que indica que la gran diferencia estadística existente entre los neandertales y HAM en la producción de adornos y de útiles óseos, no parece deberse sólo a las propiedades del suelo.

La escasa representación de adornos y de tecnología ósea no puede ser una característica cultural de todos los chatelperronienses y, por extensión, de los neandertales en general, pues su representatividad estadistica en el total de su población en este periodo es muy limitada. Su existencia es más una rareza que una generalidad, y como tal debe ser entendida y estudiada, al menos hasta que nuevos descubrimientos indiquen otra cosa. Sin embargo, algunos neandertales si fueron capaces de elaborar, con tecnologia propia, tales adornos y útiles óseos. Ambos procesos, la creación de estos objetos por parte de algunos neandertales y su ausencia en la mayoría de los yacimientos chatelperronienses y en todos los demás atribuidos al Neandertal, deben ser explicados. Estas escasas manifestaciones de simbolismo moderno indican que el Chatelperroniense y Uluzziense son unas culturas del Paleolítico Superior en el sentido cronológico y tec- 
nológico (con su industria lítica). Sólo en algunos núcleos se presentaron las características simbólicas del Paleolítico Superior, posiblemente debido a la proximidad de poblaciones modernas, dándose en ambos sentidos las condiciones necesarias para tal desarrollo (Rivera Arrizabalaga, 2008, 2008a).

Tradicionalmente, a todas las culturas europeas transicionales que no estuvieran relacionadas con el Auriñaciense se les ha atribuido a los neandertales. La ausencia de fósiles asociados a las mismas dificulta la elaboración de teorias opuestas. Además, el concepto de que los HAM entraron en Europa portando un Auriñaciense más o menos elaborado, impide asociar a esta población otro tipo de culturas. El concepto de la llegada a nuestro continente de poblaciones modernas portadoras de una tecnología laminar, pero sin la elaboración simbólica o tipológica propia del Auriñaciense, abre el debate sobre la posibilidad de que algunas culturas del este de Europa pudieran ser originadas por los HAM. Es el caso de aquellas que tienen gran semejanza tecnológica con las industrias del Próximo Oriente (levallois laminar), y tienen un carácter intrusivo respecto de las demás culturas de la zona como el Bohuniciense (Marks, 1983; Svoboda, 1986, 2002; Svoboda et al., 1996; Kuhn et al., 1999; BarYosef, 2006; Mellars, 2006) o tengan elementos suficientes (Bachokiriense) como para compararlas con el llamado Auriñaciense de los Zagros, (Kozlowski y Otte, 2000; Harrold y Otte, 2001; Olszewski y Dibble, 2006). Estas poblaciones, por motivos desconocidos (posiblemente de carácter demográfico, climático y de supervivencia), emigraron al este de Europa, donde llegaron con una tecnología que podemos definir como Paleolítico Superior Inicial (IUP), con un sentido más tecnológico que moderno en el aspecto simbólico. El problema es la falta de conexión geográfica, y la correlación paleoantropológica.

No obstante, lo que sí es seguro es que con la llegada de los HAM se produciria una interacción poblacional con las neandertales, provocaron nuevos problemas sociales, logísticos y demográficos. Estos, acrecentados por las características climáticas del momento, forzaron la creación de nuevas conductas más complejas y adaptativas (reflexividad y flexibilidad conductual). Ambos grupos pudieron desarrollar diversos tipos de conductas simbólicas de forma simultánea (Auriñaciense arcaico, Chatelperroniense y Uluzziense), aunque con características y grado de desarrollo diferentes. Serian el reflejo conductual de su respectivo desarrollo cognitivo, facilitado y limitado a sus propias capacidades psicobiológicas. Así pues, lo más llamativo fue la existencia simultánea de conductas con diferente grado de desarrollo cognitivo: sin simbolismo (Musteriense tardío, Musteriense con puntas de Chatelperron sin tecnología laminar) y con simbolismo (Chatelperroniense clásico, Auriñaciense arcaico con puntas de Chatelperron y abundantes elementos de sustrato, Auriñaciense arcaico sin elementos musterienses, Fu- mariense, etc.). Hay que destacar que los dos modelos de desarrollo cognitivo y conductual tuvieron lugar prácticamente en un mismo periodo de tiempo, (Fortea Pérez, 1999; Maillo et al., 2001; Maroto et al., .2005), posiblemente de carácter independiente el tecnológico y más relacionado con las poblaciones el simbólico (Rivera Arrizabalaga, 2008, 2008a). Esta compleja producción, junto con el estancamiento cultural de otros grupos de neandertales, es causa del típico aspecto de mosaico (Straus, 2005).

Sobre cual pudo ser la primera cultura en iniciar el camino de la modernidad, la controversia parece que va continuar, por lo menos hasta que no se consigan cronologías más exactas y una correlación antropológica bien establecida. No obstante, si hay que indicar la prioridad de alguna, es necesario realizar un detallado análisis de las características de todo el proceso de desarrollo cultural. Primero, los antecedentes culturales de los HAM en África (McBrearty y Brooks, 2000; D'Errico, 2003; Mellars, 2005), donde aparecen algunas de las características de la conducta moderna con anterioridad al Paleolítico Superior europeo y, desde luego, con mayor complejidad que en los antecedentes de los neandertales en el Paleolítico Medio. Además, el registro arqueológico europeo es mucho más intensivo y extensivo que el africano, lo que confirma con mayor exactitud esta diferencia conductual. Segundo, el inicio y desarrollo cultural de los HAM ofrece una generalizada reflexividad y flexibilidad conductual. Mientras que los neandertales ofrecen una mayor diversidad cultural pero con diferente nivel simbólico, dando la impresión de cierta fragmentación social y cultural, así como una importante desigualdad de su desarrollo cognitivo. Tercero, su propia evolución temporal con la desaparición del neandertal y de todas las culturas que se le atribuyen, indica una menor capacidad de adaptación a la nueva situación demográfica, social y ambiental de este periodo, siendo aprovechado por los HAM para su supervivencia y expansión.

\section{CONCLUSIONES}

Es difícil entender la conducta humana si pasamos por alto las causas que más trascendencia va a tener en su producción. Sus capacidades cognitivas, junto con las características medioambientales y las relaciones sociales necesarias para su desarrollo, constituyen elementos primordiales en todo estudio humano, y más aún en los periodos históricos donde la información es tan escasa. Desde el punto de vista cultural, este lejano periodo presenta una característica que lo hace muy especial, pues es en él cuando comienza la conducta moderna y el simbolismo que va a caracterizar a nuestro comportamiento de forma permanente y distintiva. Tal hecho se debió a la suma de diversos procesos que, al actuar en conjunto, dieron lugar a una conducta totalmente nueva, 
diferente y con unas características adaptativas no vistas hasta entonces. Las capacidades cognitivas evolutivamente adquiridas, y su desarrollo por medio de los diversos factores sociales y medioambientales del momento, son las causas básicas de todo el proceso. La diferente evolución, que dio lugar a los dos grupos humanos presentes en Europa (Neandertales y HAM), produjo dos modelos de desarrollo cognitivo diferentes, aunque semejantes por tener parecidas características psicobiológicas de su común ancestro evolutivo. En definitiva, tenemos la manifestación cultural de las dos Humanidades que poblaron Europa.

Las manifestaciones culturales de estas dos Humanidades tuvieron un desarrollo parecido, constituyendo el continuum histórico que caracteriza a todo proceso realizado por las acciones humanas. El simbolismo que dio lugar a la conducta moderna fue la culminación de una serie de factores (tecnológicos, sociales y demográficos), que, al actuar sobre las diferentes propiedades psicobiológicas de estas dos poblaciones, favoreció el desarrollo de las conductas que vemos en el registro arqueológico. Así, dependiendo del momento en que se encuentren estas poblaciones en su continuum cultural, así será su definición conductual y su grado de asimilación al concepto de Paleolítico Superior (tecnológico, social y/o simbólico).

Existe un proceso clave en este entramado conductual: el lenguaje humano. El lenguaje es una pieza fundamental en la comunicación y la acción de los seres humanos, al ser el medio por excelencia para transmitir los conceptos abstractos que van a marcar nuestra conducta. Su desarrollo, hasta los niveles necesarios para establecer un cambio conductual de tipo moderno, se produjo cuando en poblaciones humanas, con suficientes capacidades cognitivas, confluyeron problemas demográficos, sociales y ambientales de tal magnitud que obligaron a producir conductas más adaptativas. Constituye la primera conducta simbólica humana, y sólo cuando adquiere las características modernas (individualidad ubicada en el tiempo y el espacio), es cuando las demás conductas simbólicas pueden desarrollarse.

\section{BIBLIOGRAFIA}

AdAmS, B., 1998: "The Middle to Upper Palaeolithic Transition in Central Europe". BAR International Series, 639.

Álvarez MunÁRRIZ, L., 2005: "La conciencia humana". En La conciencia humana: perspectiva cultural. Coord. por Luis Álvarez Munárriz, Enrique Couceiro Domínguez. Barcelona. Anthropos.

ANDREW, L. y ChARLES R. P. (eds.), 1996: Editorial introducción a Parte III: "Ontogeny: symbolic development and symbolic evolution". En Handbook of Human Symbolic Evolution. Oxford. Clarendon Press.

Ardila, A.; Ostrosky-Solis, F., 2008: "Desarrollo Histórico de las Funciones Ejecutivas". Revista Neuropsicología, Neuropsiquiatría y Neurociencias, 8, 1-21.

Arrizabalaga, A. y Altuna, J., 2000: "Labeko Koba (País Vasco): Hienas y Humanos en los albores del Paleolítico superior". Munibe, 52.

BAFFIER, D., 1999: Les deniers Néandertaliens. Le Châtelperronien. Paris. La maison des roches.

BAR-YoSEF, 0., 2006: "Defining the Aurignacian". En Bar-Yosef, 0. y Zilhão, J.(eds.), Towards a definition of the Aurignacian. Proceedings of the Symposium held. Lisboa. Portugal.

BEAURE, S., 1999: "De la pierre à l'os: ou comment reconstituer des chaînes techniques opératoires impliquant l'os et la pierre". En CampsFabrer, H. Préhistoire D'os: recueil d'études sur l'industrie osseuse préhistorique. Université de Provence.

BELINCHÓN, M.; IGOA, J. M. Y RIVIĖRE, A., 1992: Psicología del lenguaje. Investigación y teoría. Madrid. Trotta.

Bermúdez De CAstro, J. M. y Dominguez-Rodrigo, M., 1992: "Heterochrony and the paleoanthropological record: the origins of the genus Homo reconsidered". Trabajos de Prehistoria, 49, 51- 68.

BICKERTON, D., 2009: Adam's Tongue: How Humans Made Language, How Language Made Humans. New York: Hill and Wang.

BoËDA, E., 1990: De la surface au volume, analyse des conceptions, des débitages Levallois et laminaire. Paléolithique moyen et Paléolithique supérieur ancian en Europe. Memóires du Musée de Prehistoire d'lle de Fance 3.

Bogin, B., 1999: "Evolutionary Perspective on Human Growth". Annu. Rev. Anthropol, 28, 109-53.

Bordes, F., 1984: "Leçons sur le Paléolithique. Vol.I. Le Paléolithique en Europa". Cahiers du Quaternaire 7. Paris. CNRS.
BORDES, J-G., 2003: "Lithic taphonomy of the Châtelperronian/Aurignacian interstratifications in Roc de Combe and Le Piage (Lot, France)". Trabalhos de Prehistoria, 223-244.

Broglio, A.; Angeluccl, D. E.; Peresani, M.; Lemorini, C. y Rosseti, P., 1996: "L'industrie protoaurignacienne de la Grotta di Fumane: donnees preliminaires". XIII U.I.S.P.P. Congress Proceedings. Forli, 8-14.

BRUNER, J., 1984: Acción, pensamiento y lenguaje. Madrid. Alianza.

BRUNER, J., 1988: Desarrollo cognitivo y educación. Madrid. Morata.

BRUner, E.; MAnZI, G. y ARSUAGA, J. L., 2003: "Encephalization and allometric trajectories in the genus Homo: Evidence from the Neanderthal and modern lineages". PNAS. 100 (26), 15335.

BufILL, E. y CARBONELL, E., 2004: "Conducta simbólica y neuroplasticidad: ¿un ejemplo de coevolución gen-cultura?" Revista de neurología 39 (1), 48-55.

Cabrera, V.; Maillo, J. M.; Lloret, M. y Bernaldo De Quirós, F., 2001: "La transitión vers le Paléolithique supérieur dans la grutte du CastiIlo (Cantabrie, Espagne): la couche 18". L'Anthropologie 105, 505532.

CAMPS, G., 1979: Manuel de Recherche Préhistorique. Paris. Doin.

Carbonell, E.; Cebrià, A.; Allué, E.; Cáceres, I.; Castro, Z.; Diaz, R.; Esteban, M.; Ollé, A.; Pastó, I.; Rodriguez, X. P.; Rosell, J.; Sala, R.; Vallverdú, J.; VAqueRo, M. Y Vergés, J. M., 1996: "Behavioural and organizational complexity in the Middle Palaeolithic from the Abric Romani". En E. Carbonell y M. Vaquero (eds.) The Last Neandertals. The First Anatomically Modern Humans. 251-266. Tarragona. URV.

Cela Conde, C. J., 2002: "La filogénesis de los homínidos". Diálogo filosófico, 53, 228-258.

ChangeuX, J. P., 1985: El hombre neuronal. Madrid. Espasa Calpe.

ChurChILL, S. E., 1988: "Could Adaptation, Heterochrony, and Neanderthals". Evolutionary Anthropology, 7, 45-60.

ConARD, N. J. y Bolus, M., 2003: "Radiocarbon Dating the Appearance of Modern Humans and Timing of Cultural Innovations in Europe: New Results and new Challenges". Journal of Human Evolution 44, 333-373.

Coolidge, F. L. y WYNN, T., 2004: "A cognitive and neuropsychological perspective on the Châtelperronian". Journal of Anthropological Research 60, 55-73.

DAMASIO, A. R., 1999: El error de Descartes. Barcelona. Crítica. 
Demars, P. Y., 1996: "Démographie et occupation de l'espace au Paléolithique supérieur et au. Mésolithique en France". Préhistoire européenne, 8, 3-26.

D'ERRICO, F., 2003: "The Invisible Frontier. A Multiple Species Model for the Origin of Behavioural Modernity". Evolutionary Anthropology, $12,188-202$.

D’errico, F.; Zilhao, J.; Julien, M.; Baffier, D. y Pelegrin, J., 1998: "Neanderthal acculturation in western Europe? A critical review of the evidence and its interpretation". Current Anthropology, 39 (supl.), $1-44$.

D'errico, F.; Henshilwood, Ch.; Lawson G.; Vanhaeren, M.; Tillier, A. M.; Suressi, M.; Bresson, F.; Maureille, B.; Nowell, A.; Lakarra, J.; BackWELL, L. Y JULIEN. M., 2003: "Archaeological Evidence for the Emergence of Language, Symbolism, and Music-An Alternative Multidisciplinary Perspective". Journal of World Prehistory, 17 (1), $1-70$.

DJINDJIAN, F.; KOZLOWSKI, J. y OTTE, M., 1999: Le Paléolithique supérieur en Europe. Paris. Armand Colin.

Edelman, G. M. y TonONI, G., 2000: Un Universe of Consciousness. New York. Basic Books.

Eiroa, J. J.; Bachiller Gil, J. A.; Castro Pérez, L. y Lomba Maurandi, J., 1999: Nociones de tecnología y tipología en Prehistoria. Barcelona. Ariel.

ELDREDGE, N. Y Gould, S. J., 1972: "Punctuated equilibria; an alternative to phyletic gradualism". En T. J. M. Schopf (ed.): Models of Paleobiology, San Francisco; Freeman, Cooper.

Elías, N., 1990: La sociedad de los individuos. Ensayos. Barcelona. Península / Ideas.

ELiAs, N., 1992: Time: An Essay. London. Basil Blackwell.

ESPARZA, J., 1995: La cueva de Isturiz, su yacimiento y sus relaciones con la Cornisa Cantábrica durante el Paleolítico superior. Madrid. UNED.

FlÉBlot-Augustins, J., 1993: "Mobility strategies in the late Middle Palaeolithic of central Europe and western Europe: elements of stability and variability". Journal of Anthropological Archaeology 12, 211-65.

Flórez, J.; García-Porrero, J. A.; Gómez, P.; Izouierdo, J. M.; Jimeno, A. y GómEz, E. , 1999: Genes, cultura y mente: una reflexión multidisciplinar sobre la naturaleza humana en la década del cerebro. Santander. Servicio de publicaciones de la Universidad de Cantabria.

ForteA PÉREZ, J., 1999: "Abrigo de La Viña. Informe y primera valoración de las campañas 1995 a 1998". Excavaciones Arqueológicas en Asturias 1995-1998. 31-42.

GAMBLE, C., 2001: Las sociedades paleolíticas de Europa. Barcelona. Ariel.

GINTER, B. et al., 1996: "Transition in the Balkans: news from the Temnata Cave, Bulgaria". En E. Carbonell y M. Vaquero (eds.) The Last Neanderthals, The First Anatomically Modern Humans. 251-266. Tarragona. URV.

Gómez Pellón, E., 2005: "Conciencia y cultura", en L. Álvarez Munárriz (ed.), La conciencia humana: perspectiva cultural. Barcelona. Anthropos, 135-191.

GonZÁlez LABRA, M. J., 1998: Introducción a la Psicología del Pensamiento. Valladolid. Trotta.

GouLD, S. J., 1991: "Exaptación: A crucial tool for evolutionary psychology". Journal of Social Issues. 47, 43-65.

GRANGER, J.-M.; LÉVÊQUE, F. , 1977: "Parure castelperronienne et aurignacienne: étude de tríos séries inédites de dents percées et comparaisons". Compte-rendu de l'Académie de Sciences. 325, 537-543.

HARALD, F., 2003: "Did they meet or not? Observations on Châtelperronian and Aurignacian settlement patterns in eastern France". En Zilhão, J. y d'Errico, F. (eds.), The chronology of the Aurignacian and of the transitional technocomplexes: dating, stratigraphies, cultural implications. Trabalhos de Arqueología 33.

Harrold, F. B. y OTte, M., 2001: "Time, Space, and Cultural Process in the European Middle". En Questioning the Answers: Re-solving Fun- damental Problems of the Early Upper Palaeolithic. Hays, M. y Thacker, P.(eds.). BAR international Series 1005.

HenshilwOOd, C. S. y MAREAN, C. W., 2003: "The Origin of Modern Human Behaviour: Critique of the Models and Their Test Implications". Current Anthropology 41 (5), 627-651.

HeRnANDO, A., 1999: "Percepción de la realidad y Prehistoria, relación entre la construcción de la identidad y la complejidad socio-económica en los grupos humanos". Trabajos de Prehistoria. 56 (2), 19-35.

HuBlin, J. J., 1999: "Derniers néandertaliens et premiers européens modernes". Pour la Science h.s. 22, 110-118.

JENKINS, R., 1996: Social Identity. New York y London, Routledge.

Jenkins, W. M.; Merzenich, M.; OChs, M. T.; Allard, T. y Guic-Robles, E., 1990: "Functional reorganization of primary somatosensory cortex in adult owl monkeys after behaviourally controlled tactile stimulation". J. Neurophysiol, 63, 82-104.

Just, M. A.; Carpenter, P. A.; Keller, T. A.; Eddy, W. F. y Thulborn, K. R., 1996: "Brain activation modulated by sentence comprehension". Science, 274, 114-116.

Johnson, M., 2000: Teoría arqueológica. Barcelona. Ariel.

Kandel, E. E., Schwart, J. H. y JeSEll, T. M., 1997: Neurociencia y conducta. Madrid. Prentice Hall.

KLEIN, R. G., 1994: "The problem of modern humans origins". En Origins of anatomically modern humans. Nitecki, M. H. y Nitecki, D. V. (eds.). New York: Plenum Press.

KozlowsKI, J. K. y OTTE, M., 2000: "The formation of the Aurignacian in Europe". J. Anthropol. Res. 56, 513-534.

KUnn S. L. y StineR, M., 1998: "The Earliest Aurignacian of Riparo Mochi (Liguria, Italy)". Current Anthropology 39, supplement 3, 175-188.

Kunn, S. L. y BietTI, A., 2000: "The Late Middle and Early Upper Paleolithic in Italy". En The Geography of Neandertals and Modern Humans in Europe and Greater Mediterranean. Bar-Yosef, 0. y Plibeam, D. (eds.). 49-75. Cambridge, Massachusetts: Peabody Museum of Archaeology and Ethnology, Harvard University.

KUHN, S. L.; StIneR, M.; GÜLEÇ, E., 1999: "Initial Upper Palaeolithic in south-central Turkey and its regional context: a preliminary report". Antiquity 73, 505-517.

LALUEZA FoX, C., 2005: Genes de neandertal. Madrid. Sintesis.

LenNeBerG, E. H., 1976: Fundamentos biológicos del lenguaje. Madrid. Alianza.

LÉVÊOUE, F., 1993: "Les données du gisement de Saint Césaire et la transition Paléolithique moyen/supérieur en Poitou-Charentes". En Cabrera, V. (ed.). El origen del hombre moderno en el suroeste de Europa. Madrid. UNED. 263-286.

LÉVI-Strauss, C., 1964: El pensamiento salvaje. México. Fondo de Cultura Económica.

LEWIS-WILLIAMS, D., 2005: La mente en la caverna. Madrid. Akal.

LURIA, A. R., 1966: Higher Cortical Function in Man. New York. Basic Books.

Maillo, J. M.; Valladas, H.; Cabrera, V. y Bernaldo De Quirós, 2001: "Nuevas dataciones para el Paleolítico Superior de cueva Morín (Villanueva de Villaescusa)". Espacio, Tiempo y Forma. Serie I. Prehistoria y Arqueología 14, 145-150.

Maroto, J.; Vaquero, M.; Arrizabalaga, A.; Baena, J.; Carrión, E.; Jordá, J. F.; Martinón, M.; Menéndez, M.; Montes, R. y Rosell, J., 2005: "Problemática cronológica del final del Paleolítico Medio en el Norte Peninsular". Neandertales cantábricos. Estado de la Cuestión. El Paleolítico Medio cantábrico: hacia una revisión actualizada de su problemática. Santander. Museo de Altamira. Monografías, 20. 101-114.

MARKS, A. E., 1983: "The sites of Boqer Tachtit and Boqer: a brief introduction". En Marks, A. E., ed. Prehistory and paleoenvironments in the Central Negev, Israel, vol. III. The Avdat/Aqev Area, Part 3. Dallas, TX: Southern Methodist University Press, 15-37.

McBEARTY, S. y BROOKS, A., 2000: "The revolution that wasn't: a new interpretation of the origin of modern human behaviour". Journal of Human Evolution 39, 453-563. 
Mellars, P. A., 1989: "Major issues in the emergence of modern humans". Current Anthropology 30, 349-385.

MeLLARS, P. A., 1999: "The Neanderthal problem continued". Current Anthropology 40 (3), 341-350.

MellaRS, P. A., 205: "The Impossible Coincidence. A Single-Species Model for the Origins of Modern Human Behaviour in Europe". Evolutionary Anthropology 14, 12-27.

MeLLARS, P., 2006: "Archaeology and the Dispersal of Modern Humans in Europe: Deconstructing the "Aurignacian». Evolutionary Anthropology.15, 167-182.

Mellars, P.; Gravina, B. y Ramsey, C. B., 2007: "Confirmation of Neanderthal/modern human interstratification at the Chatelperronian type-site". PNAS, 104 (9), 3657-3662.

Menéndez Fernández, M.; Garcia Sánchez, E. y Quesada López, J. M., 2005: "La transición Paleolítico Medio-Paleolítico Superior en la Cueva de la Huelga (Cangas de Onis, Asturias). Un avance de su registro". Neandertales cantábricos. Estado de la Cuestión. El Paleolítico Medio cantábrico: hacia una revisión actualizada de su problemática. Santander. Museo de Altamira. Monografías, 20, 589-617.

Mithen, S., 1998: Arqueología de la mente. Barcelona. Critica.

MoRA, F., 2001: El reloj de la sabiduría. Tiempos y espacios en el cerebro humano. Madrid. Alianza.

Morales Grajera, P. J., 1998: "Yacimientos Chatelperronienses en el Norte de España". Espacio, Tiempo y Forma. Serie I, Prehistoria y Arqueología, 11.

NoBlE, W. y DAVIDSON, I., 1996: Human Evolution, Language and Mind. Cambridge: Cambridge University Press.

OLSZEWSKI, D. Y DIBBLE, H., 2006: "To be or not to be Aurignacian: the Zagros Upper Palaeolithic". En Bar-Yosef, 0. y Zilhão, J.(eds.), Towards a definition of the Aurignacian. Lisboa. Proceedings of the Symposium held.

OTte, M. y Straus, L. G., 1995: Le Trou Magritte: Fouilles 1991-1992. Liège. ERAUL

Palma Di Cesnaola, A. , 1993: I/ Paleolitico superiore in Italia. Garlatti e Razzai, Firenze.

PELEGRIN, J. y SORESSI, M., 2007: "Le Châtelperronien et ses rapports avec le Moustérien". En Les Néandertaliens. Biologie et cultures. Documents préhistoriques, 23, 283-29.6 Paris, Éditions du CTHS.

PIKe-TAY, A. Y KNeCht, H., 1993: "La caza y la transición del Paleolítico Superior". En V. Cabrera (ed) El origen del hombre moderno en el suroeste de Europa. Madrid. UNED.

RAKIC, P., 1995: "Evolution of neocortical parcellation: the perspective from experimental neuroembryology", en Changeux, J. P. y Chavaillon J. (eds.). Origins of the human brain. Oxford. Clarendon Press. 85-100.

RévilLon, S. Y TuffreAu, A., 1994: "Les industries laminares au Paléolithique moyen". Dossier de documentation arqueologique 18. Paris. CNRS.

RILING, J. K., E INSEL, T. R., 1999: "The primate neocórtex in comparative perspective using magnetic resonance imaging". Journal of Human Evolution, 37, 191-223.

Rivera Arrizabalaga, A. , 1998: "Arqueología del lenguaje en el proceso evolutivo del Género Homo". Espacio, Tiempo y Forma. Serie I, Prehistoria y Arqueología 11, 13-43.

Rivera ArRizabalaga, A., 2003-2004: "La conducta simbólica humana: Nueva orientación metodológica". Espacio, Tiempo y Forma. Serie I, Prehistoria y Arqueología, 16-17, 313-335.

Rivera Arrizabalaga, A., 2004: "Arqueología cognitiva. Una orientación psicobiológica". ArqueoWeb 6 (1). (UCM). URL: http://www.ucm.es/info/arqueoweb/index.htm.

Rivera Arrizabalaga, A., 2004a: "Paleoclimatología y cronología del Würm reciente: Un intento de síntesis". Zephyrus. LVII, 27-53.

Rivera ArRizabalaga, A., 2008: "Relación entre Neandertales y Cromañones: un enfoque cognitivo". Zephyrus, LXI.

Rivera ArrizabalAga, A., 2008a: "Cognición y conducta de neandertales y humanos modernos". Revista Portuguesa de Arqueología. Vol. $11(1), 5-32$.
Rivera ArRizabalaga, A., 2009: Arqueología del lenguaje. La conducta simbólica en el Paleolítico. Madrid. Akal.

SeARLE, J. R., 2000: El misterio de la conciencia. Barcelona. Paidos.

SemenDEFERI, K. Y DAMASIO, H., 2000: The brain and its main anatomical subdivisions in living hominoids using magnetic resonance imaging. Journal of Human Evolution, 38, 317-332.

SemendeferI, K.; Lu, A.; SchenkeR, N. y DAmAsIO, H., 2002: Humans and great apes share a large frontal cortex. Nature neuroscience 5 (3), 272-276.

Semenov, S. A., 1957: Tecnología Prehistórica. Estudio de las herramientas y objetos antiguos a través de las huellas de huso. Madrid. Akal, (1981).

SHenNAN, S., 2001: "Demography and Cultural Innovation: A Model and Its Implications for the Emergence of Modern Human Culture". Cambridge Archaeology Journal 11, 5-16.

SINHA, CH. G., 1996: "The role of ontogenesis in human evolution and development", en Andrew, L. y Charles R. P. (eds): Handbook of Human Symbolic Evolution. Oxford. Clarendon Press.

SkoYLES, J. R., 1999: Neural plasticity and exaptation. American Phychologis, 54, 438-39.

Stiner, M. C.; Munro, N. D.; Surovell, T. A.; TChernov, E. y BAR-Yosef, O., 1999: "Palaeolithic Population Growth Pulses Evidenced by Small Animal Exploitation". Science, 283, 190-194.

StRAUS, L. G., 1996: "Continuity or rupture: convergence or invasion: adaptation or catastrophe: mosaic or monolith: view on the Middle to Upper Paleolithic transition in Iberia". En E. Carbonel y M. Vaquero (eds.): The Last Neandertals, The First Anatomically Modern Humans. 51-76. Tarragona. URV.

StrauS, L. G., 2005: "A mosaic of change: the Middle-Upper Palaeolithic transition as viewed from New Mexico and Iberia". Quaternary International. 137, 1, 47-67.

Stringer, C. B. y Davies, W. , 2001: "Those elusive Neanderthals". Nature 413,791

TRINGeR, C. y GAMBLE, C., 1996: En busca de los Neandertales.. Barcelona. Crítica.

SvoвodA, J., 1986: "The Homo sapiens neanderthalensis/Homo sapiens sapiens transition in Moravia. Chronological and archaeological background". Anthropos (Brno), 23, 237-242.

SvoBODA, J., 2002: "The Bohunician and the Aurignacian". En Zilhão, J. y d'Errico, F. (eds.), The chronology of the Aurignacian and of the transitional technocomplexes: dating, stratigraphies, cultural implications. Trabalhos de Arqueologia 33.

SVOBODA, J.; LOZEK, V.; VLCEK, E., 1996: Hunters between East and West. The Palaeolithic of Moravia. New York and London. Plenum Press.

TABorIN, Y., 1993: "La parure en coquillage au Paléolithique". Gallia Préhistoire, suplement 29. Paris. CNRS.

TURO, A., 1993: "L'approvisionnement en matières premièrers lithiques au Moustérien et au début du Paléolithique supérier dans le nordest du basin Aquitain (France)". En Cabrera Valdés, V. (ed.): El origen del hombre moderno en el suroeste de Europa. Madrid. UNED.

VANHAEREN, M.; D'ERRICO, F., 2006: "Aurignacian ethno-linguistic geography of Europe revealed by personal ornaments". Journal of Archaeological Science, 33, 1105-28.

VYGoTSKY, L. S., 1979: El desarrollo de los procesos psicológicos superiores. Barcelona. Critica.

WHITE, R., 1983: "A technological View of Castelperronian and Aurignacian Body Ornaments in France". En V. Cabrera (ed): El origen del hombre moderno en el suroeste de Europa. Madrid. UNED.

WILKINS, W. Y DUMFORD, J., 1990: "In defence of exaptation". The Behavioural and Brain Sciences. 13, 763-764.

WynN, T. Y Coolidge, F. L., 2004: "The expert Neanderthal" mind. Journal of Human Evolution 46, 467-487.

Yravedra SÁInZ de los TerReros, J., 2002: "Subsistencia en la transición del Paleolítico Medio al Paleolítico Superior de la Península Ibérican. Trabajos de Prehistoria 59 (1), 9.

YUSTE, R., 1994: "Desarrollo de la corteza cerebral". Investigación y Ciencia, 214, 62-68. 
ZILHÄO, J., 2007: "The Emergence of Ornaments and Art: An Archaeological Perspective on the Origins of Behavioral Modernity". Journal of Archaeological Research, 5 (1), 1-54.

ZııнÄO, J., 2008: Modernos y Neandertales en la transición del Paleolitico medio al superior en Europa. Espacio, Tiempo y Forma. Serie I, Nueva época. Prehistoria y Arqueología, 1, 47-58.

ZILHÄO, J. Y D'ERRICO, F., 1999: "The chronology and taphonomy of the earliest Aurignacian and its implications for the understanding of Neandertal extintion". Journal of World Prehistory 13 (1), 1-68.
ZILhÄO, J.; D'ERRICO, F.; BORdeS, J-G.; LenOBle, A.; TeXIER, J-P.; RigAud, J-P., 2006: "Analysis of Aurignacian interstratification at the Châtelperronian-type site and implications for the behavioral modernity of Neandertals". Proceedings of the National Academy of Sciences. Washington, DC 103: 33, 12643-12648.

ZilhäO, J.; D'ERRICO, F.; BORdes, J-G.; LenOBle, A.; TeXIER, J-P.; Rigaud, J-P., 2008: "Grotte des Fées (Châtelperron): History of Research, Stratigraphy, Dating, and Archaeology of the Châtelperronian Type-Site". PaleoAnthropology. Pennsylvania, 1-42. 